Doi: www.doi.org/10.25130/tjaes.17.55.1.14

\title{
واقع تطبيق بعض استر اتيجيات التصنيع الأخضر في المنظمات العراقية معمل اسمنت بادوش في محافظة نينوى أنموذجاً
}

\author{
م.د. علي ذنون يونس أحمد الجادر \\ كلية علوم البيئة وتقاناتها \\ جامعة الموصل \\ alialjader@uomosul.edu.iq
}

المستخلص

يسعى البحث إلى التعرف على إمكانية اعتماد بعض استراتيجيات التصنيع الأخضر

و المتمثلة بالأبعاد (التقليص، التدوير و إعادة الاستعمال) في المنظمة قيد البحث عن طريق دراسة تللك المنظمة و على تنوع المستويات الادارية، و التي تعكس مدى اهتمامها بتحقيق اهدافها لاديا البيئية،

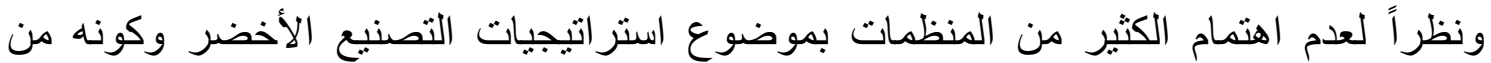

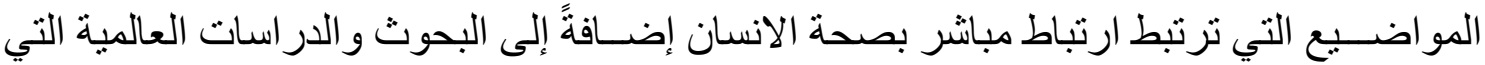

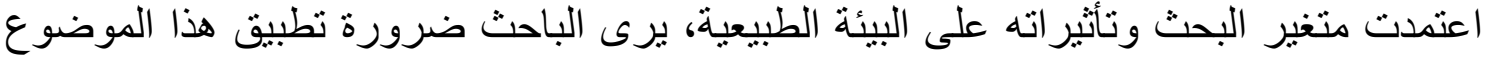
في المنظمة المبحوثة لما لها من تأثثير مباشر على محافظة نينوى بشكل خاص و العر اق بشكل عام

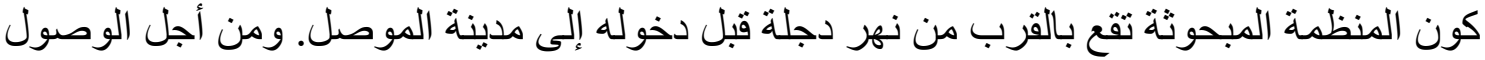

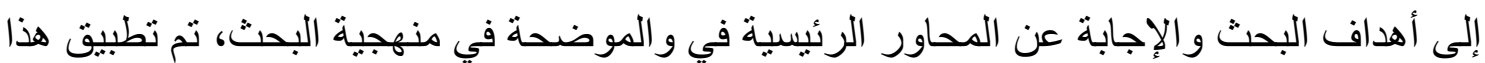

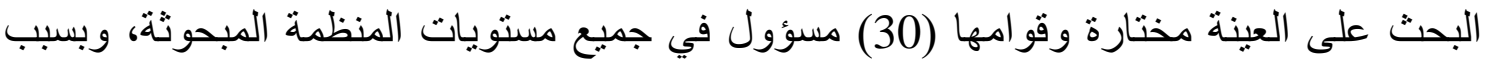

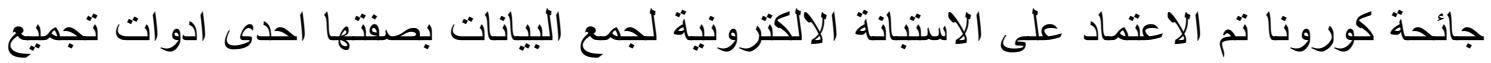
البيانات، فمن خلال مخرجات برنامج (AMOS) تم التوصل اللى نتائج التحليل العاملي التوكيدي،

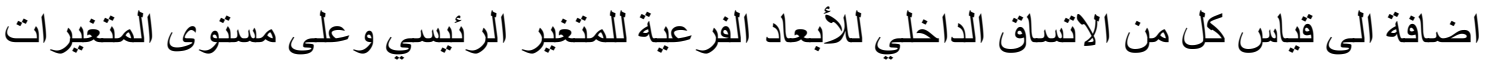

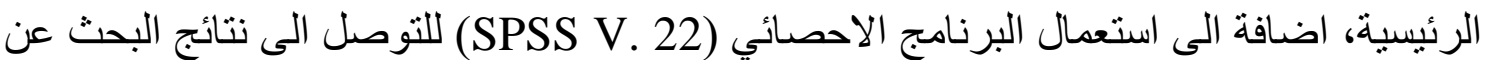

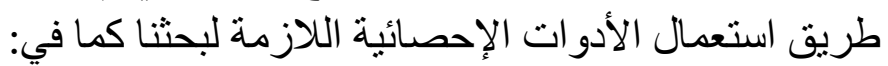
Arithmetic mean, standard deviation, coefficient of variance, and T.test ومن خلال النتائج توصل البحث إلى مجموعة من الاستنتاجات والمقترحات، من بينها ضرورة تبني موضوع استر اتيجيات التصنيع الأخضر كثقافة سائدة في المنظمات العر اقية كونها

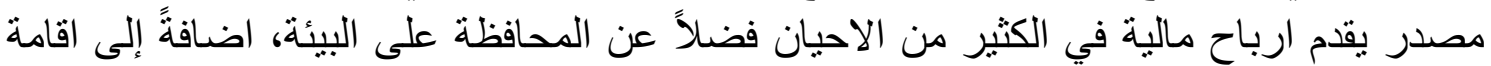

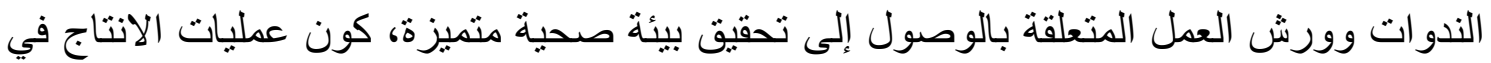

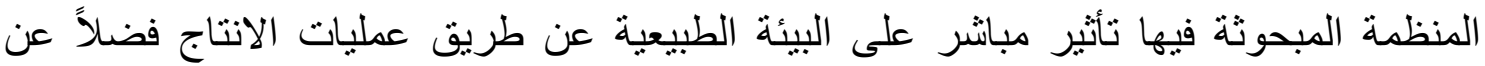
المخلفات التي تطمر فيها كون نهر دجلة بيعد 2 كيلومتر عن مركز المنظمة المبحوثة. الكلمات المفتاحية: المنظمة الخضر اء، استراتيجيات التقليص، استر اتيجية التدوير، استر اتيجية 


\title{
The reality of the application of some green manufacturing strategies in Iraqi organizations \\ The Badush Cement Factory in Nineveh Governorate as a model
}

\author{
Lecturer Dr. Ali Thanoun Younis Ahmed Al-Jader \\ College of Environmental Sciences and Technologies \\ University of Mosul
}

\begin{abstract}
The research seeks to identify the possibility of adopting some green manufacturing strategies represented by dimensions (reduction, recycling and reuse) in the organization under consideration by studying that organization and on the diversity of administrative levels, which reflects the extent of its interest in achieving its environmental goals, and due to the lack of interest in many organizations in the subject of strategies Green industrialization and being one of the topics that are directly related to human health in addition to international research and studies that have adopted the research variable and its effects on the natural environment, the researcher believes that this topic should be applied in the researched organization because of its direct impact on Nineveh Governorate in particular and Iraq in general as the researched organization It is located near the Tigris River before entering the city of Mosul.

In order to reach the objectives of the research and answer the main themes in the research methodology, this research was applied to a selected sample consisting of (30) officials at all levels of the organization in question, and because of the Corona pandemic, the electronic questionnaire was relied on to collect data as one of the data collection tools, Through the outputs of the (AMOS) program, the results of the confirmatory factor analysis were reached, in addition to measuring the internal consistency of the sub-dimensions of the main variable and at the level of the main variables, in addition to using the statistical program (SPSS V. 22) to reach the results of the research by using the tools The statistic needed for our research as in the (Arithmetic mean, standard deviation, coefficient of variance, and. T.test).

Through the results, the research reached a set of conclusions and proposals, including the need to adopt the subject of green manufacturing strategies as a prevailing culture in Iraqi organizations, as it is a source that often provides financial profits as well as preserving the environment, in addition to holding seminars and workshops related to achieving an environmentally friendly environment. Distinguished health, because the production processes in the organization in question have a direct impact on the natural environment through production processes, in addition to the waste that is buried in it, because the Tigris River is $2 \mathrm{~km}$ from the center of the organization in question.
\end{abstract}

Keywords: green organization, reduction strategies, recycling strategy, reuse strategy. 
منذ امد بعيد ونشاطات الانسان الصناعية تمثل تهديدا للطبيعة وأدى هذا التهديد مع زيادة التقدم التكنولوجي و الصناعي سيما مع بداية الثورة الصناعية مطلع القرن الماضي حصل فئل تقدماً ملحوظاً في المنظمات، عن طريق استخدامها كميات كبيرة من المواد الاولية وليدة الطبيعية

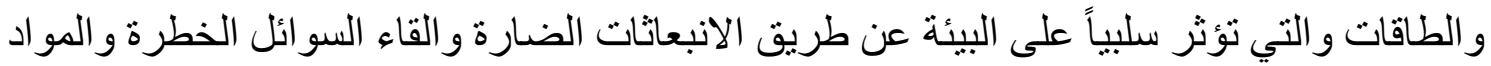

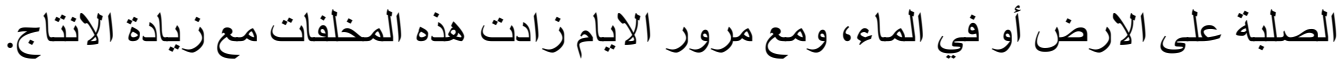

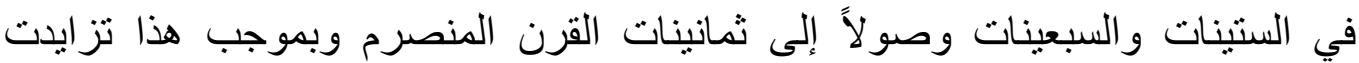
المطالبات بحماية البيئة، هذه الافراز ات اوجدت حاجة ملحة لابتكار و ايجاد اليات تصنيع مستدامة

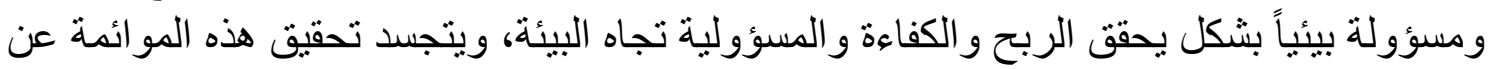

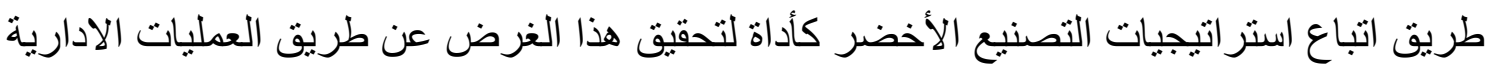
(التخطيط والتنفيذ والمراقبة والتدفق الفعال للمواد الخام وفي عملية الجرد للعمليات اللازمة للتصنيع من نقطة المنشأ إلى الاستهلاك أو التخلص السليم) مما دفع منظمات الاعمال إلى التفكير

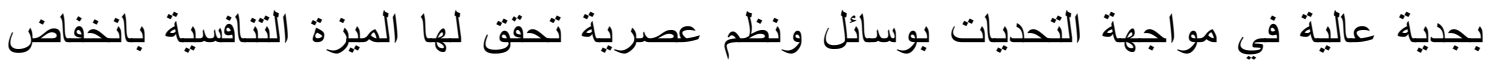
تكاليف المدخلات و المحافظة على البيئة الطبيعية لتحقيق رضا الزبون، ولتحقيق للتكامل بين البيئة الطبيعية والتصنيع ظهرت بوادر وآليات لاتباع تصنيع يهنم بالبيئة تحت مسميات عديدة منها

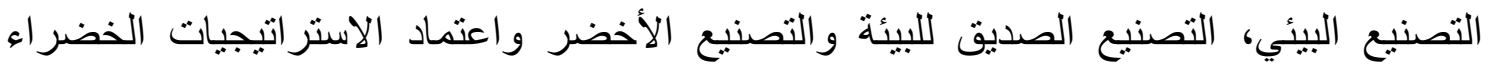

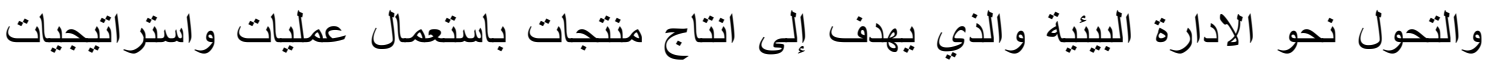
و اساليب لا تؤثر سلباً على البيئة عن طريق الاعتماد على تقنيات انتاجية عالية ضمن مقاييس معينة تتوفر فيها الموثوقية بدرجة عالية واعادة تصميم للمنتجات بشكل يجعلها قابلة للاسترداد و اعادة

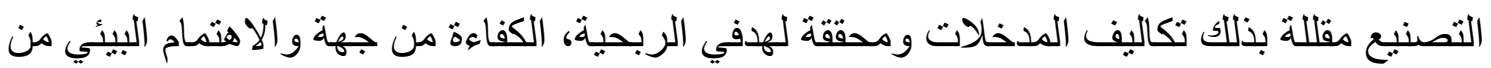
الجهة الاخرى، وبشكل عام بتضمن البحث اربعة مباحث رئيسة، اولهم منهجية البحث ويتبعه لرئه الجانب النظري للبحث، يليه الجانب الميداني للبحث وامثن واخيره الاستنتاجات و التوصيات.

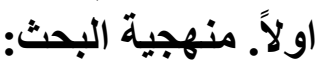
مشكلة البحث: لمو اجهة تحديات البيئة الطبيعية اليوم يتطلب من المنظمات التصدي لها وتتمثل هذه التحديات في نفاذ الموارد الطبيعية والتي تعتبر المدخلات الاولية في ابي عملية فضلاً عن قصر الئر

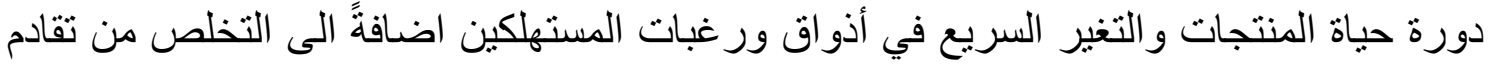

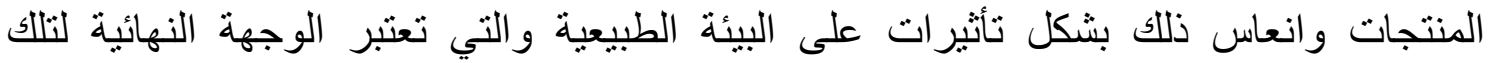
المنتجات، فعملية انتاج الاسمنت تصاحبها الكثير من العمليات والتي تؤدي إلى تأثير على البئي البيئية الطبيعية وهو ما يتطلب العمل على ايجاد اساليب بيئية لتقليل او الحد من تللك الآثار البيئية، عليه فعن طريق استعمال الاساليب العصرية في نظم الانتاج و العمليات ابتداءً من تصميم المنتوج مروراً

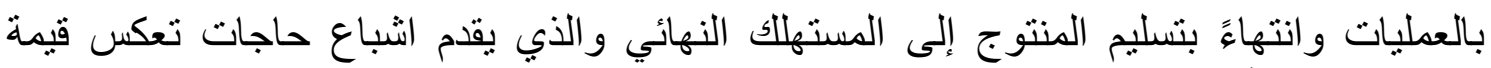

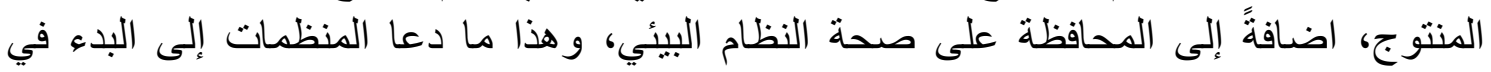

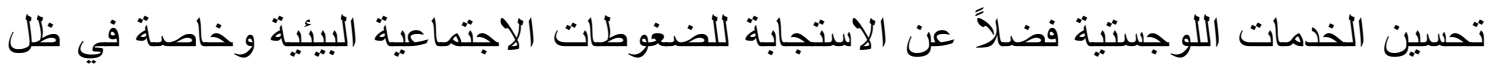
نظم الادارة البيئية حيث تجد نفسها ملزمة بتبني آليات وصيغ عمل جديدة تعبر عن استجابة

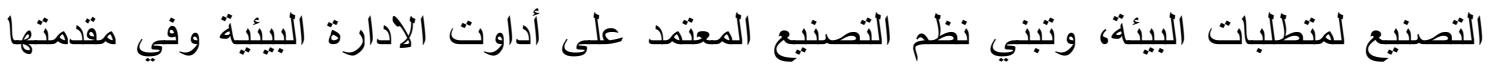
التصنيع الأخضر الذي يستثمر عن طريق استر اتيجياته كأحد متطلبات تجنب الضرى البئئئي. 
وبناءً على ما سبق بمكن تحديد مشكلة البحث بإثارة التساؤلات الآتية:

1. هل المنظمة المبحوثة تعتمد على استر اتيجية التقليص؟

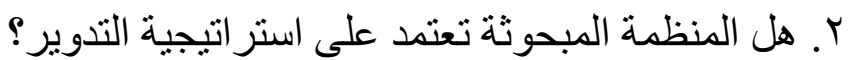

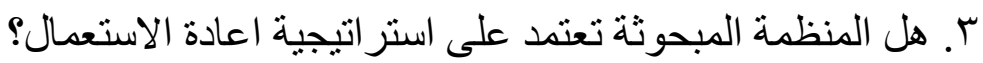
أهمية البحث: تتبين أهمية البحث عن طريق در اسة متغير اته وبصورة و اقعية، اضافة إلى تطبيقه

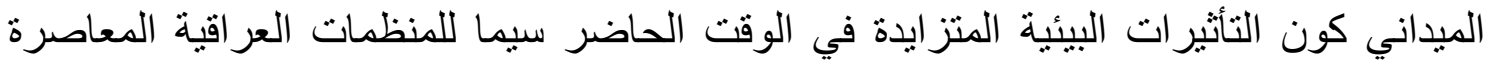

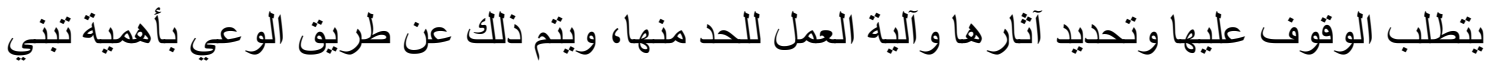
استراتيجيات تصنيع صديقة للبيئة بشكل عام فضلاً عن تطور الوعي العالمي بأهمية تفعيل استر اتيجيات التصنيع الأخضر بثكل خاص، والتي تنعكس على صحة البيئة الطبيعية عليه باتت الموضوعات البيئية من أكثر المواضيع الادارية اهمية على الصعيد العالمي، لارتباط البيئة الكبير

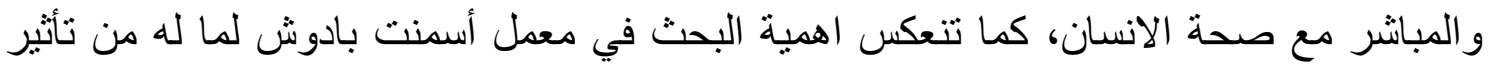
على البيئة الطبيعية، حيث يعتبر من الميادين العاملة بإعادة تدوير المنتجات لتحقيق الالتز ام البيئي

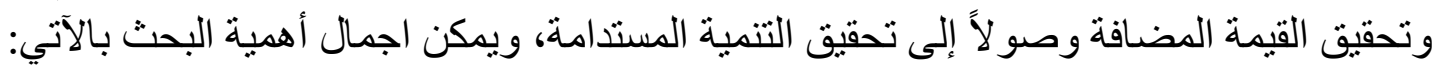

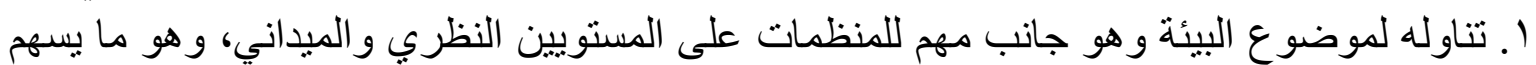
في ديمومة واستمر ار بقاء المنظمات ونمو ها. ץ. اظهار وتحديد أهمية استر اتيجيات التصنيع الأخضر كواحة لدذة من متطلبات كل من الالتزام البيئي و التنمية المستدامة، و الذي يعمل على تعزيز كل من المكانة التنافسية و القيمة الذهنية وتحقيق الجودة البيئية للمنظمات عن طريق تحقيق الكفاءة و الفاعلية البيئية. فرضية البحث: يقدم البحث الفرضيتان الاساسيتان ادناه والتي تمثل افتراضًاً لمدى توافر

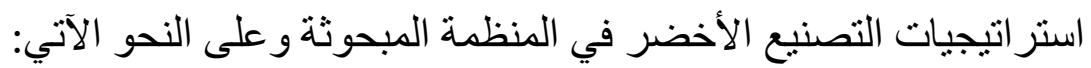

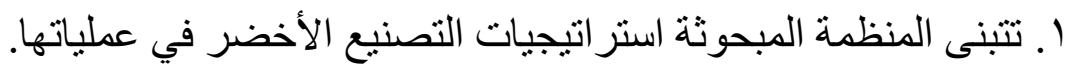
r. تباين مستوى استر اتيجيات التصنيع الأخضر من حيث التهبه التطبيق. أهداف البحث: يهدف البحث إنى إلى الآتي: ا ـ تعريف ادارة المنظمة المبحوثة بمفهوم استراتيجيات التصنيع الأخضر وضرورة تطبيقها لتحقيق

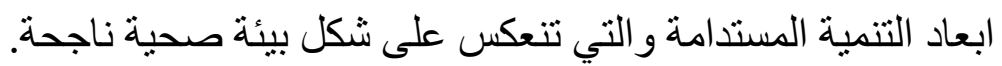

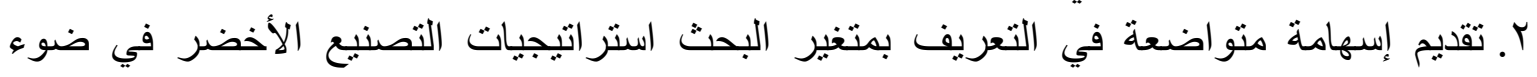
عرض الإطار النظري. ب. تحديد الو اقع الفعلي لمستوى الاهتمام باستر اتيجيات التصنيع الأخضر في المنظمة المبحوثة فضلاً عن الكثف عن امكانية تبني هذه الاستر اتيجيات. منهج البحث: للوصول إلى النتائج يتطلب الاعتماد على المنهج الوصفي والتئي التحليلي وذلك لمعالجة البيانات التي تم التوصل اليها عن طريق اداة جمع البيانات و الموضحة في (الملحق ل (ل). حدود البحث: ا ـ الحدود المكانية: معمل اسمنت بادوش في محافظة نينوى.

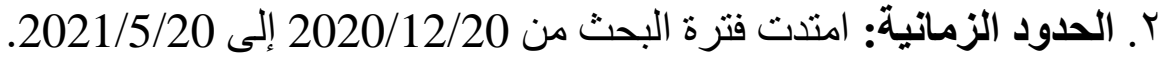
r. الحدود البشرية: السادة المسؤولين في معمل أسمنت بادوش-الموصلئ. 
اساليب وطرق الحصول البيانات: تم اعتماد الاساليب التالية في عملية جمع بيانات البحث وعلى

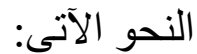

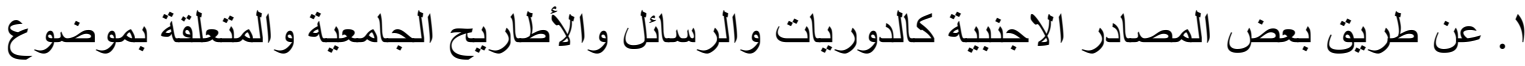

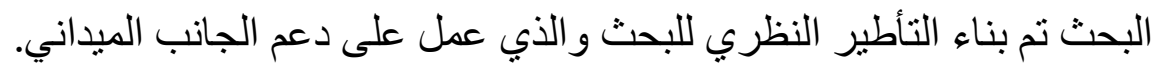

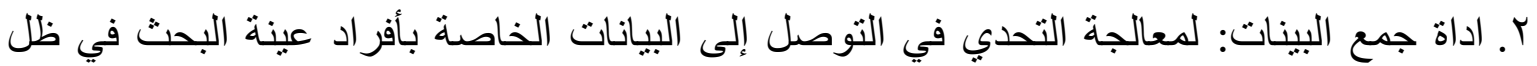

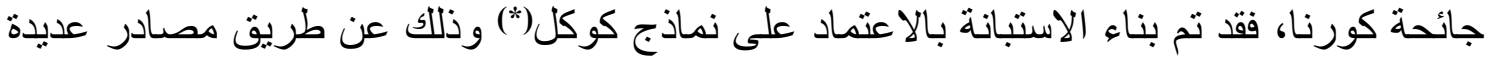

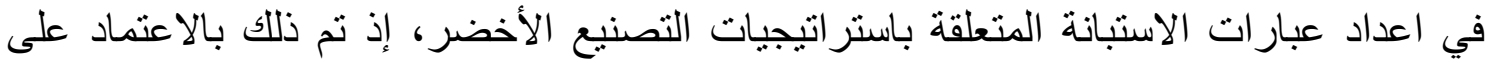

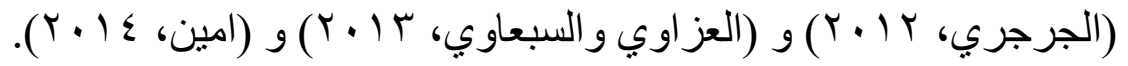

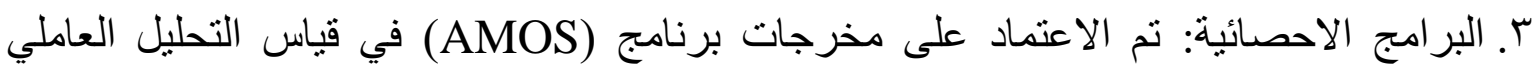
التوكيدي من الدرجة الاولى والدرجة الثانية، اضافة الى استخدام مخرجات بران برنامج (SPSSV.22) في التوصل الى المؤشرات الاحصائي (الوسط الحسابي والانحراف التانية المعياري ونسبة ما عمل

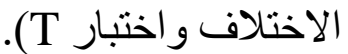

\section{المبحث الثاني: الجانب النظري للبحث}

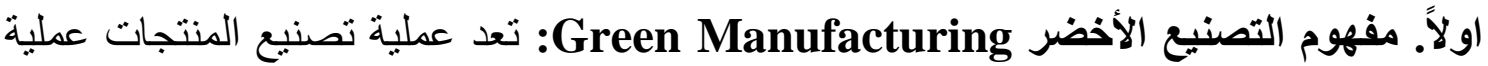

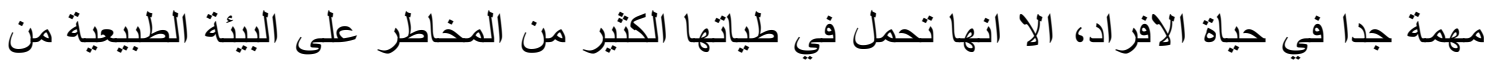

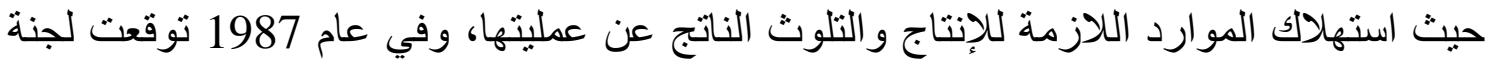

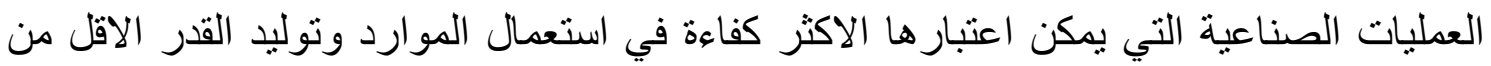

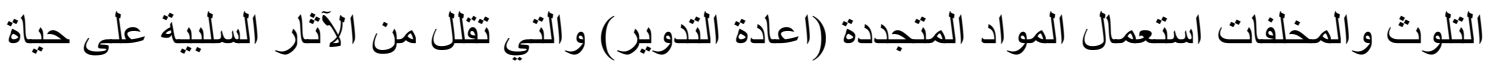

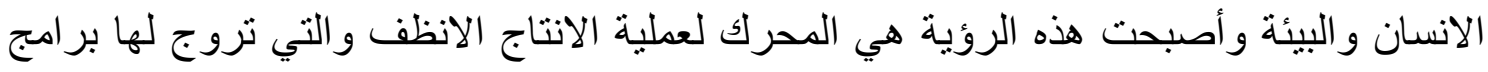

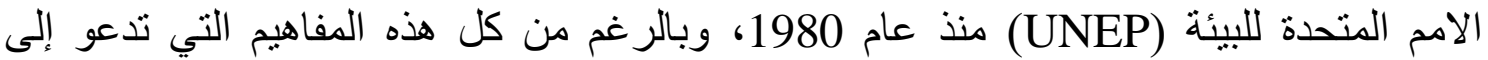

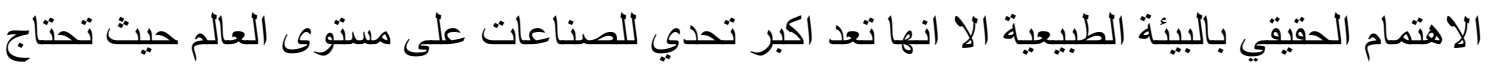

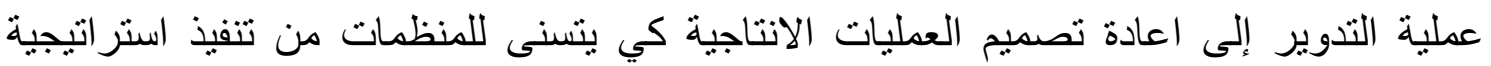

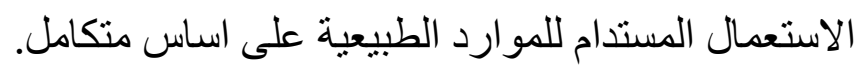

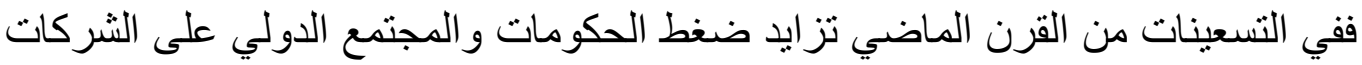

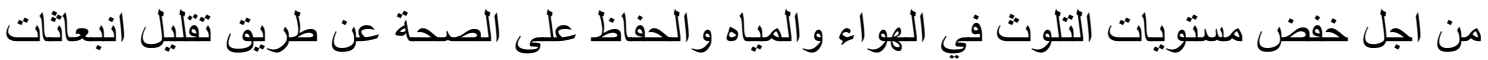

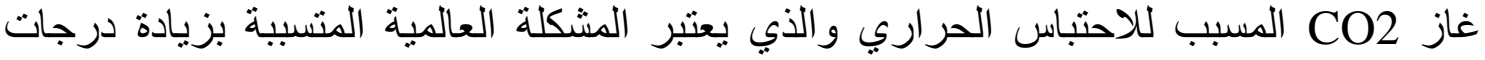
الحرارة (UNEP, 2011:248)، ويعرفه كل من (Atlas and Florida, 1998:

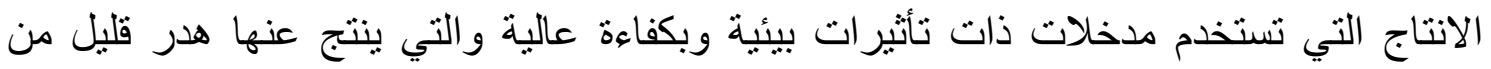
المو ارد ونسبة تلوث منخفضة. فيما اشار (Rastogi, 2001:3) إلى انه طريقة تصنيع تهدف إلى تقليل الهر و والضياع إنهاع

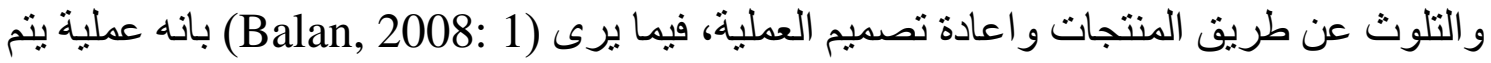

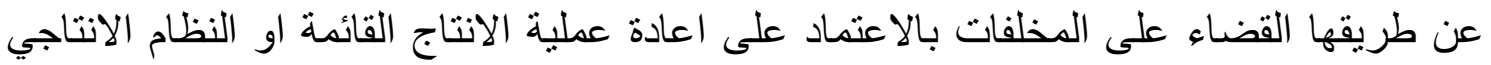

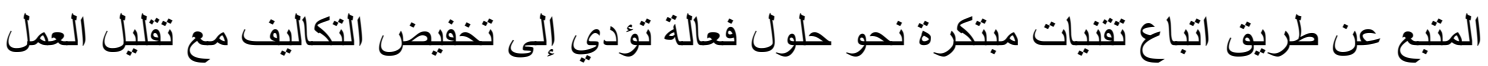

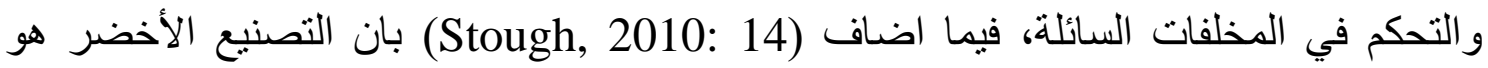


عملية تلبية احتياجات الحاضر دون المساس بقدرة الاجيال المقبلة على تلبية احتباجاتها الخاصة، ويعرفها (Bhattcharya, 2011:6) بانها عملية تهدف إلى تحقيق استدامة بيئية للحفاظ على الإنى الهو اءو المياه و الارض وض الطاقة بكفاءة واعادة تدوير المخلفات للحد من تأثثر الانسان على الانشطة

واضاف (Wyckoff, 2014:4) بان عملية التصنيع الأخضر هي وسيلة جديدة ومميزة

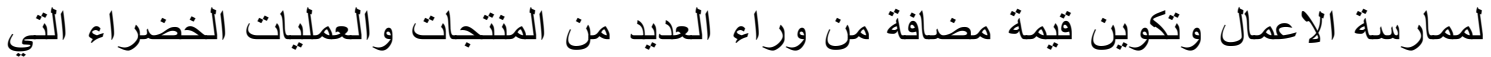

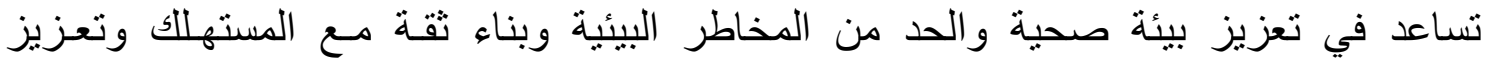

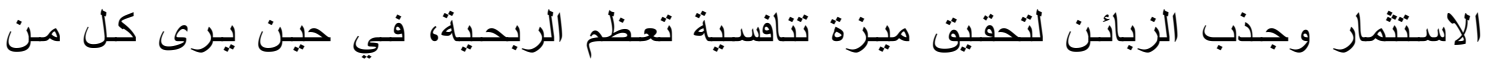

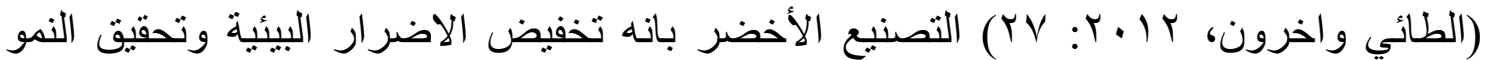

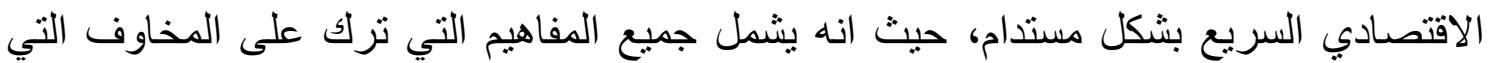

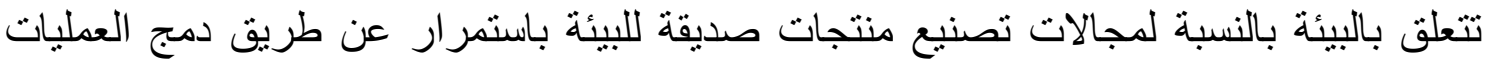
الصناعية بصورة تجعل من شأنها التخفيض من حدة التلوث من المخلفات وتقليل المخاطر التي لتئي

$$
\text { يتعرض لها البشر. }
$$

فيما يشير (Lynch et al., 2014:4) بانه عمليات تهدف إلى تقليل التشـغيل حفـاظاً

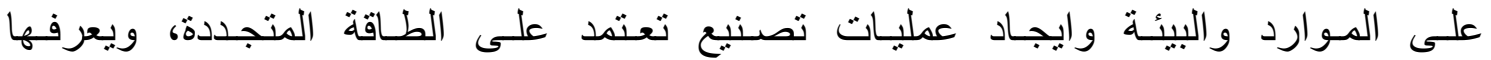

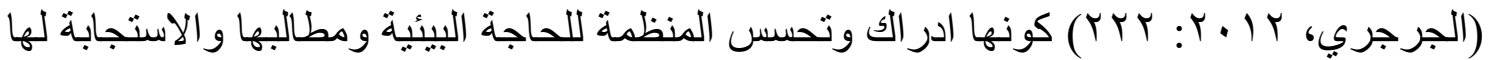

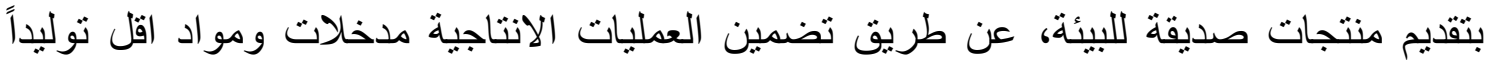

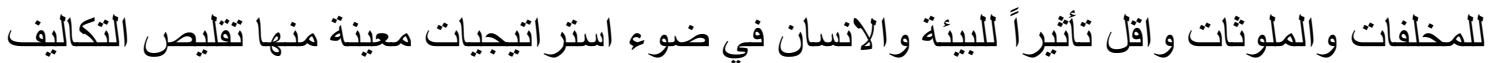

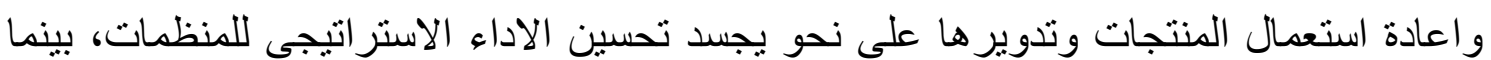

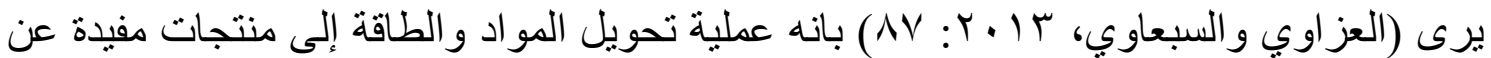

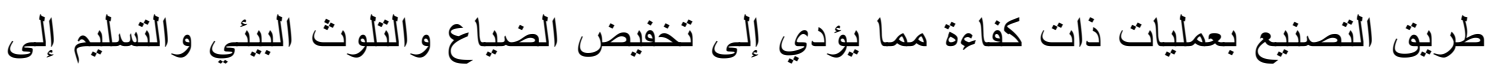

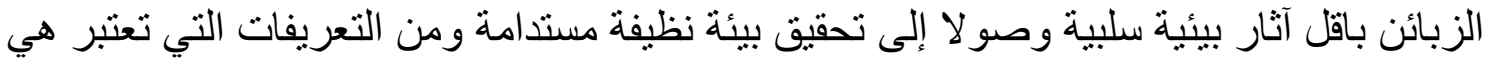

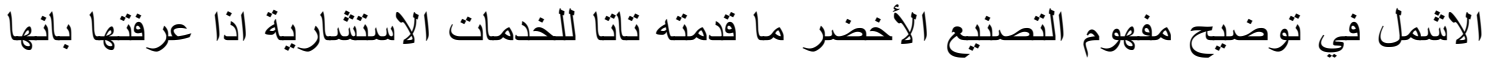

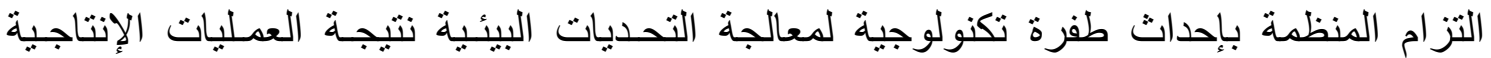
بحيث تكون المنظمة بإنتاجية انظف وأكثر كفاءة لتخفيض نسبة انبعاثات غـاز CO2

.(TATA Consultancy service, $2014: 4)$

وبناء على ما سبق يرى الباحث ان التصنيع الأخضر هو التزام المنظمة بتني تقنيات

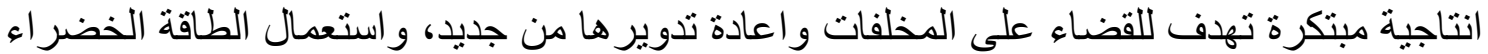

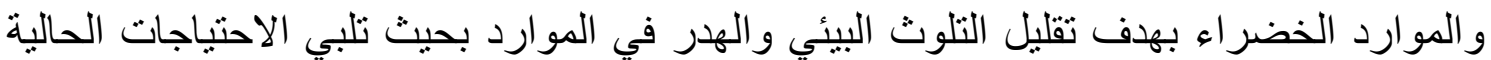
للزبائن وتحقيق الربحية دون التأثير على الطبيعة وصو لاً إلى تحقيق التنمية البيائية المستدامة.

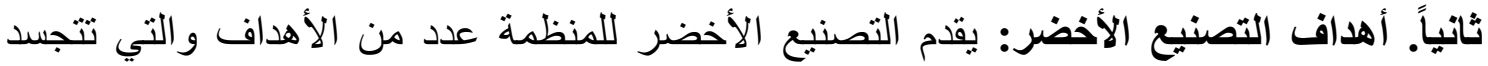

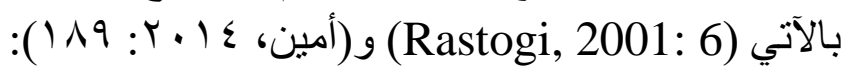
1 ا ب تعزيز الاهتمام بالوعي البيئي. r. تخفيض استعمال الموارد وتقليل الطاقة وتقليل العيل المواد السامة. كَ. تعزيز عملية التدوير وتعظيم استعمال الموارد و الطاقة المتجددة.

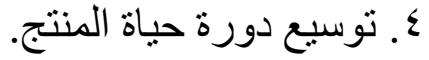


0. يوفر المال ويحافظ على راس المال. 7. بقلل التكاليف ويزيد الانتاجية.

V. تشجيع المنظمات على الالتز ام بضمان الاستدامة البيئية وصو لا إلى بيئة صحية.

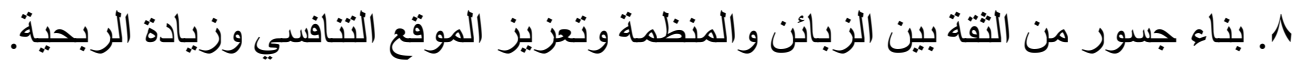

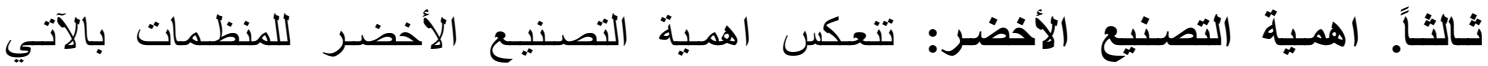

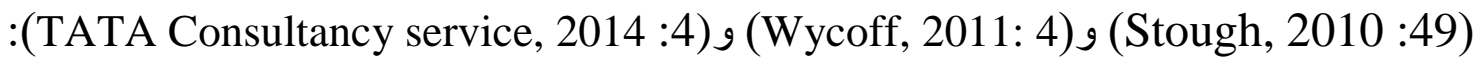
ا ل ان تكون المادة الداخلة والخارجة خلال العملية الانتاجية في طبيعتها غير خطرة.

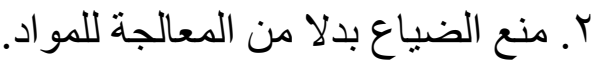

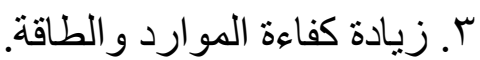
ع. تخفيض التعقيد للعمليات الصناعية و التصاميم للمنتج. 0. تقليص تنوع المو اد المستخذمة في تكوين المنتج. 7. جعل المنتجات قابلة للتذوير.

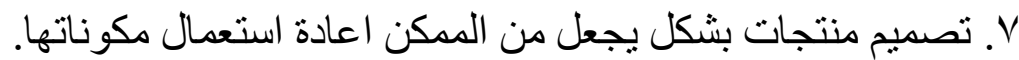

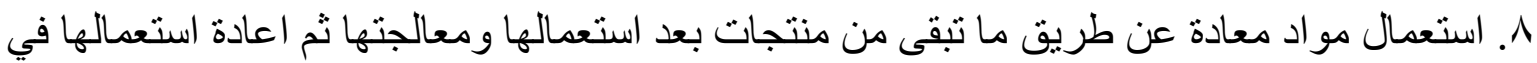
العملية النصنيعية.

9 9. دعم الاجيال المستقبلية وتحقيق الاستدامة عن طريق وسائل الحفاظ على الموارد الطبيعية.

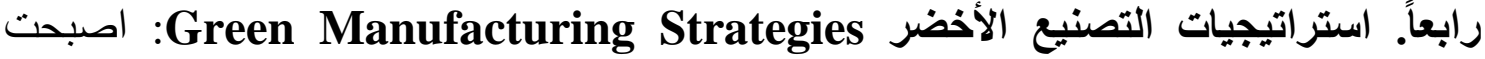

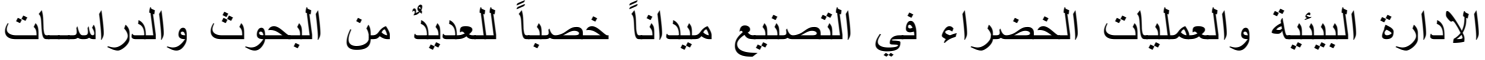

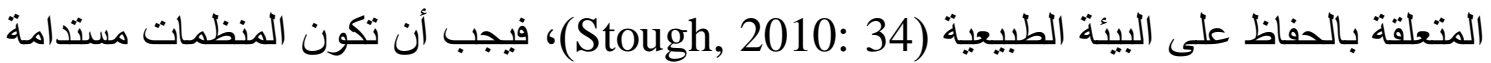

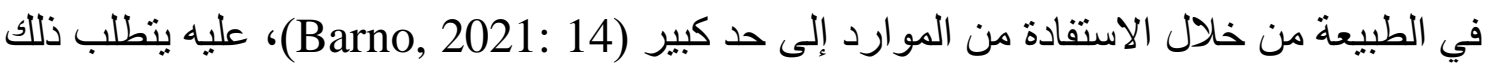

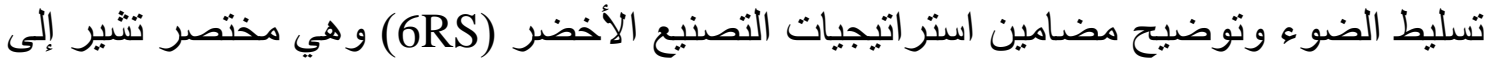

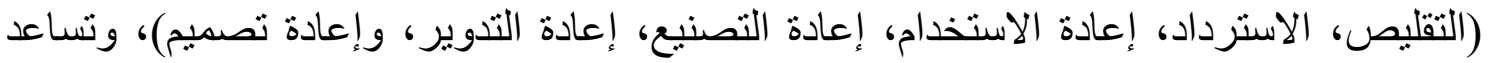

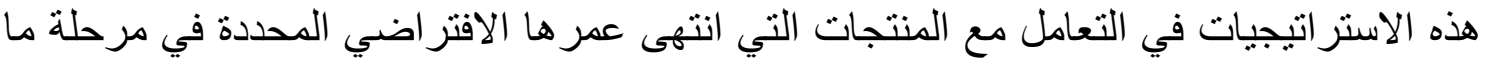

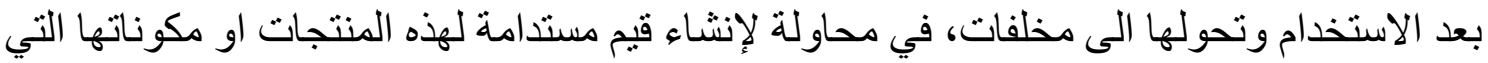

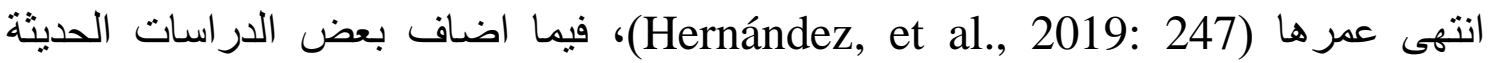
استراتيجية إعادة التفكير (Rethink) لتشكل بذللك الاستراتيجية السابعة وبذللك برمز لها الان بالرمز (Arisi, 2020: 66) و) و) (Anindita, et. al., 2021: 750).

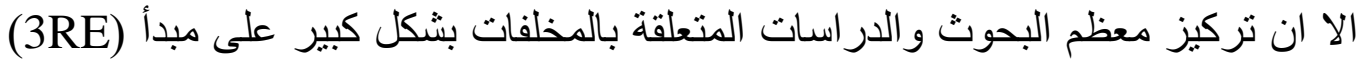
(التقليص وإعادة الاستخدام وإعادة التدوير) (Yu, et al., 2021)، عليه ففي ببحثنا تم

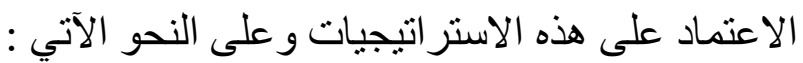

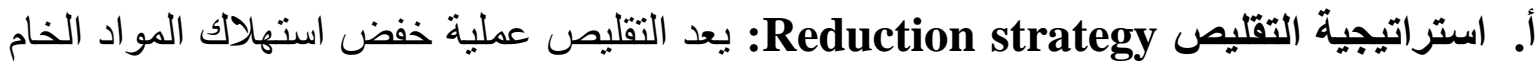

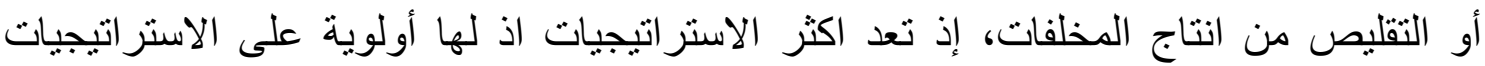

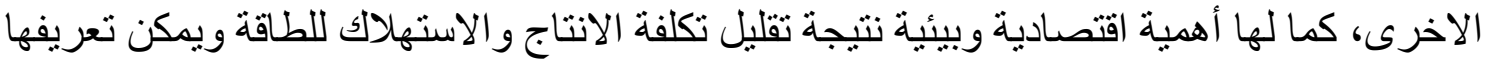

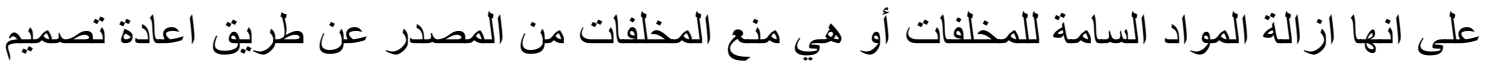

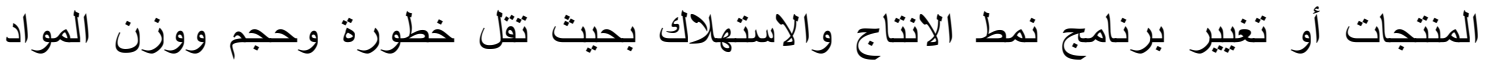

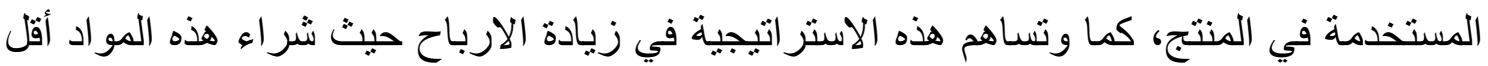


ثمنا وبالتأكيد دون المساس بالنوعية، حيث ان في المتوسط 95\% من المنظمة المصنعة تواجه

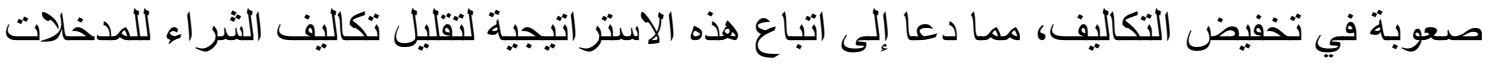

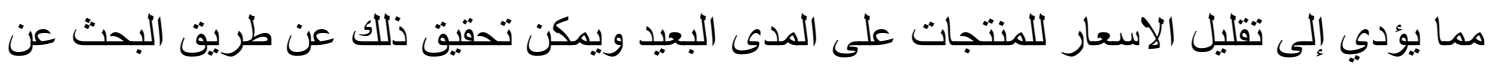

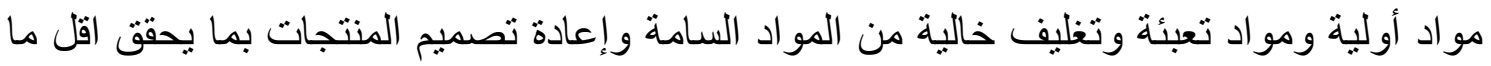

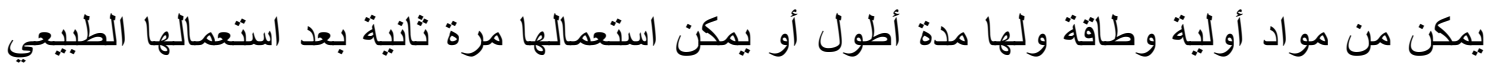

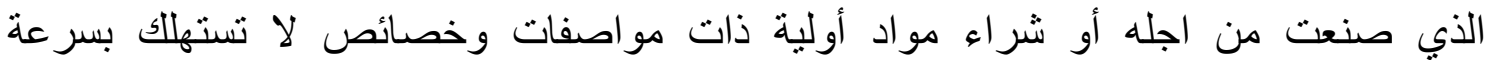

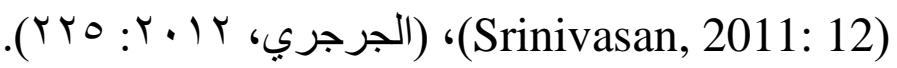
عليه فان استر اتيجية التقليص تثير الى تقليل أو تبسيط استهلاك المنتجات التئ التي يتم شراؤها و استهلاكها وإزالتها في أسرع وقت ممكن، على سبيل المثال، تقليل العبوات البلاستيكية ذات

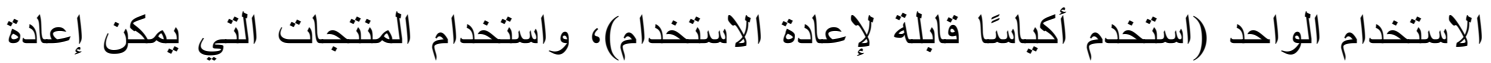

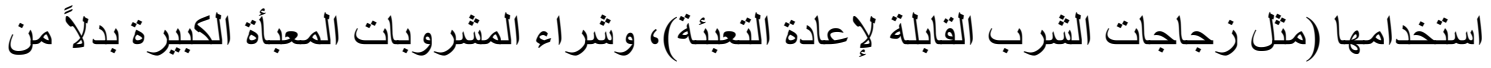
العبوات الصغيرة، وبصرف النظر عن المخلفات، يمكن لمفهوم التقليص استخدامه أيضًا في

استخدام المياه و الطاقة (Faridy and Rohendi, 2021: 484). ب. استراتيجية اعادة التدوير Recycle Strategy: و هي الاستر اتيجية المتعلقة بإعادة تدوير المنتج

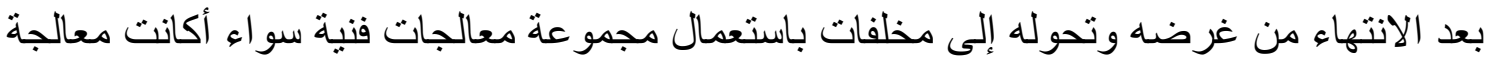

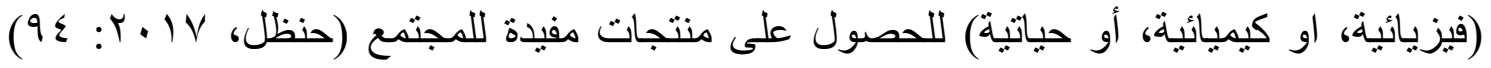

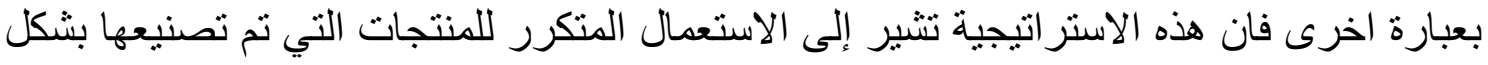

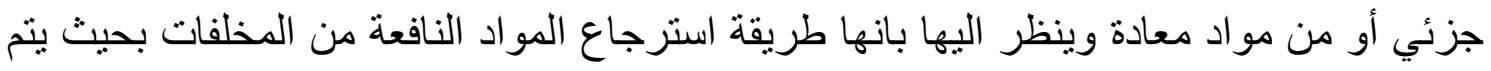

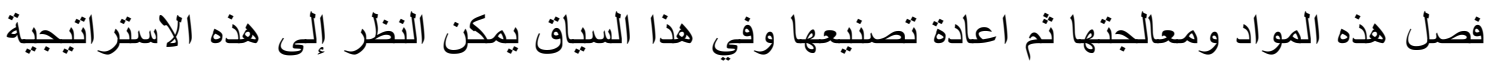

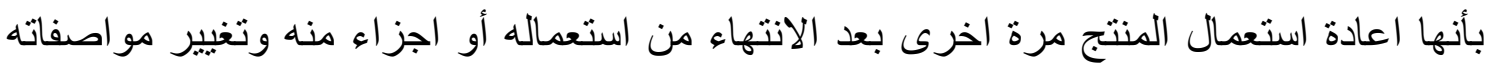

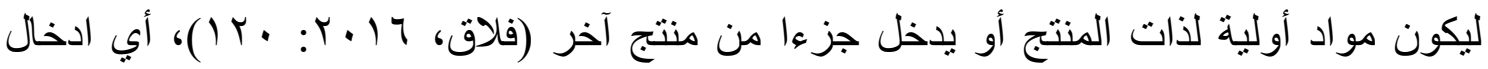

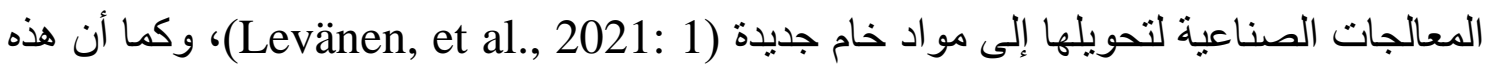
الاستراتيجية تتطلب مجموعة إجراءات كتطوير اساليب جمع وحصر انواع واعداد المخلفات (المواد) لإعادة تدوير ها وبحسب نو عها لتحقيق افضل طرق الاستعمال للمنتجات المعاد تدوير ها،

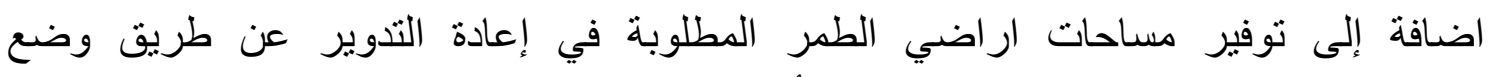
استر اتيجيات الازمة لإعادة تدوير المخلفات بأنو اعها، وتحقق هذه الاستر اتيجية مجمو عة كبيرة من

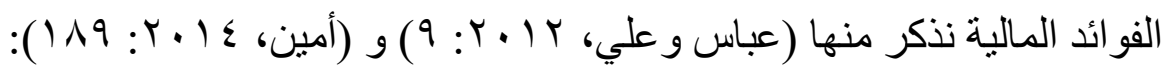

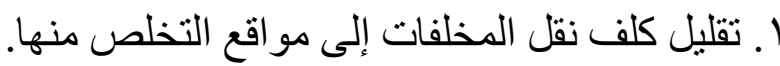
ץ. تقليل كلف الانتاج نتيجة تحسين الكفاءة في استعمال المخلفات بوصفها مو اد أولية أو الاستفادة منها

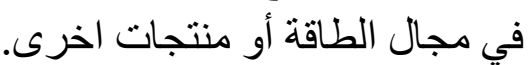
r. حماية المو ارد الطبيعية وتقليل استنز افها وخاصة المبات الموارد الغير متجددة.

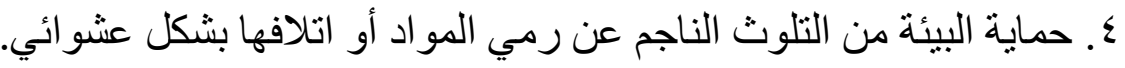

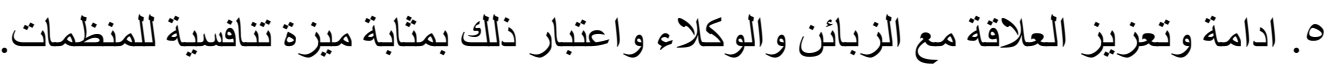

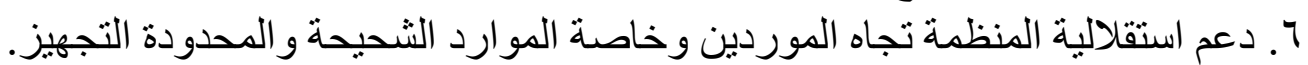
V. حصول المستهلك على عو ائد نقدية نظير اعادته للمو اد القابلة للتدوير. 
ج. استراتيجية اعادة الاستعمال Re-use Strategy: ان هذه الاستر اتيجية تنطوي على معنيين

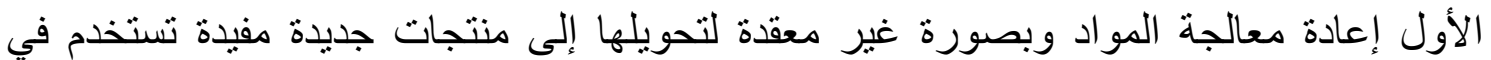

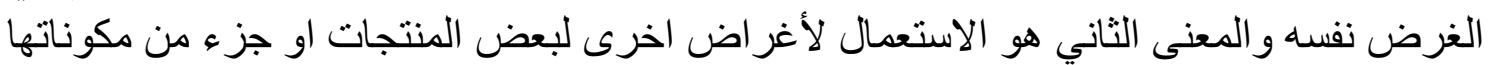

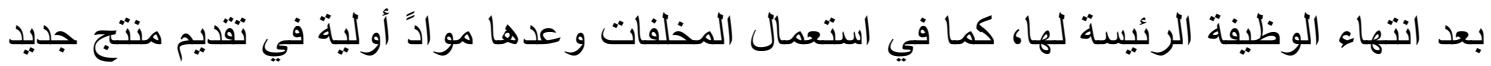
و هو يعكس بصورة مباشرة إعادة الاستعمال لمخلفات المنتجات، وتتم عملية اعادة تدوير المخلفات

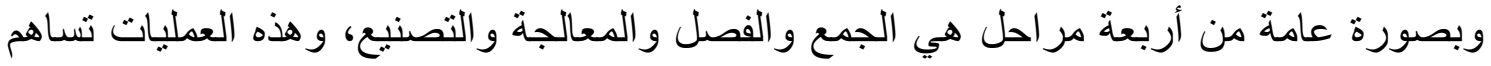

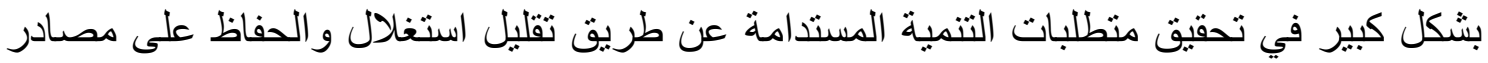
الموارد الطبيعية بالإضافة إلى خلق فرص عمل جديدة، ومن المخلفات التي يمكن تدويرها

:(GBC, 2016: 8)

ا ـ الورق بشكل عام كما في (الصحف، و المكاتب و المقوى_الكرتون).

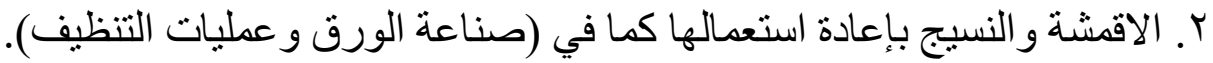
r. المعادن المختلفة كما في (الالمنيوم و الحديد). ع. اعادة صهر الزجاج.

๑ـ المطاط وذلك في تصنيع منتجات المنخفضة النو عية للعديد كما في (ارضيات الملاعب). 7. اعادة صهر اللدائن وتصنيع المنتجات الجديدة.

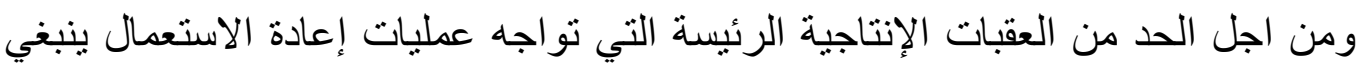

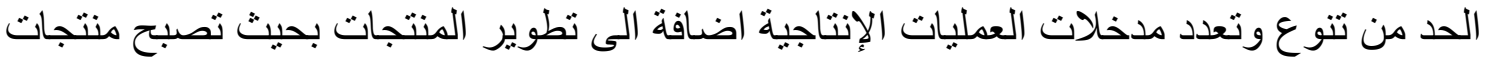

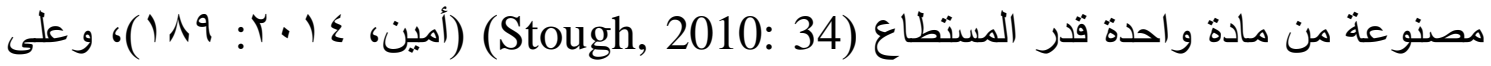
هذا الأساس تحقق هذه الاستر اتيجية توفير اً في كلف الثر اء لمواء ادو ادو ومنتجات جديدة، كما ويقلل كمية

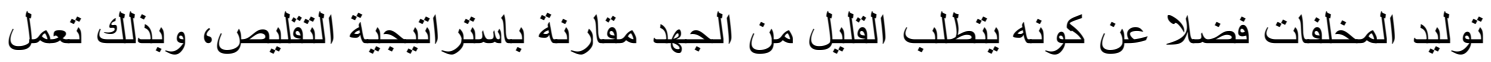
استر اتيجية إعادة الاستعمال على منع تكوين المخلفات، حيث يتم استخدام المنتج من قبل مستخدم

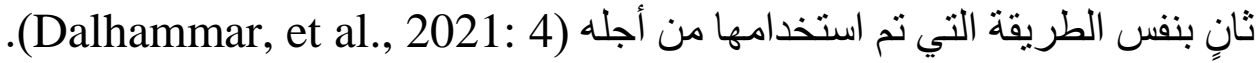
المبحث الثالث: الجاتب المبداني للبحث

اولاً. التحليل العاملي التوكيدي: ا ـ التحليل العاملي التوكيدي من الرتبة الاولى: بعمل على معرفة قوة ارتباط المشاهدات (الأسئلة)

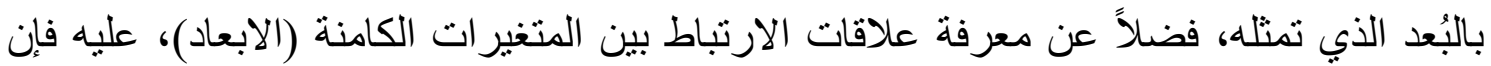
الثكل (1) يوضح مخرجات نظام (AMOS) للتحليل العاملي التوكيدي من الارجة الاولى و الي لئي

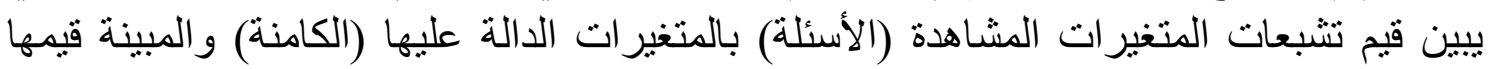

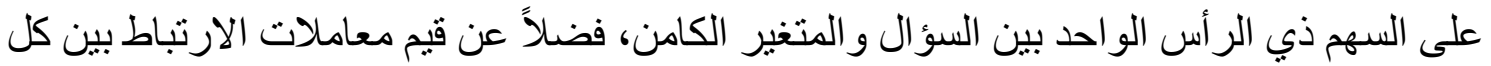

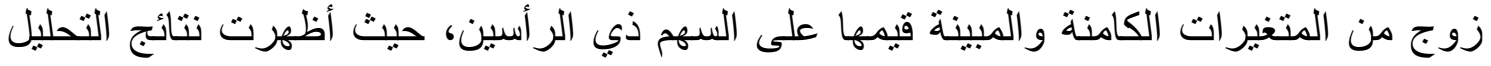
العاملي معنوية انموذج الدراسة بدلالة غالبية مؤشرات جودة المطابقة وذللك بالاعتماد على الثى مؤشر ات حسن المطابقة وحدود القبول المستخدمة من اغلب الباحثين. 


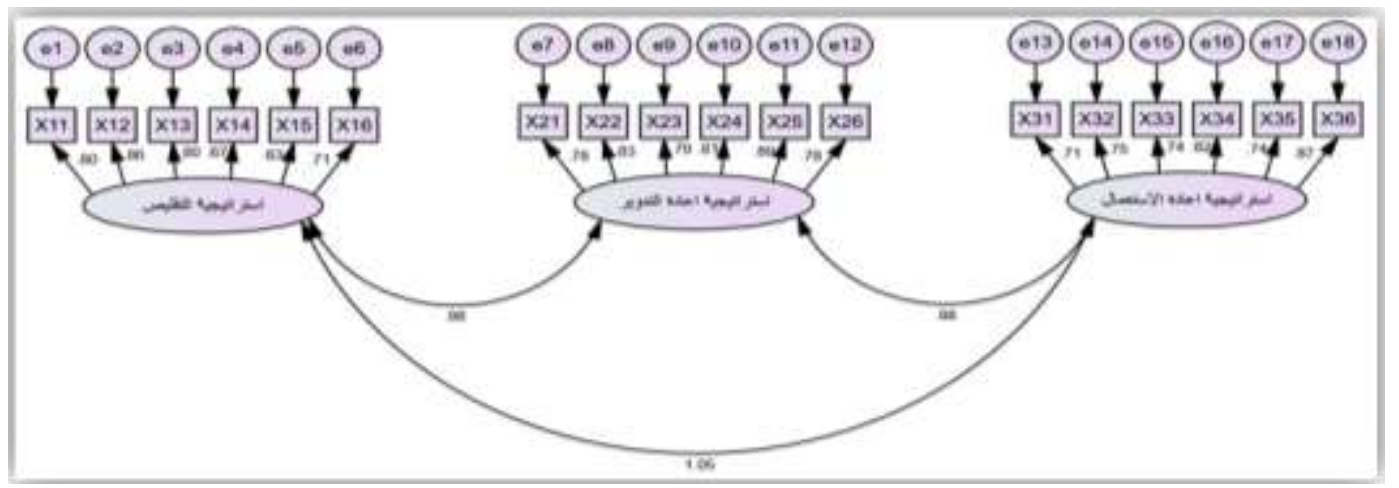

المصدر : بالاعتماد على نتائج مخرجات برنامج (AMOS).

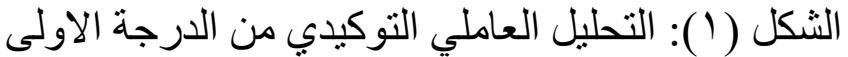

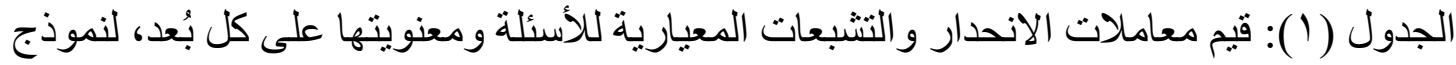
التحليل العاملي التوكيدي من الدرجة الإلهي

\begin{tabular}{|c|c|c|c|c|c|c|c|}
\hline \multicolumn{3}{|c|}{ Parameter } & Estimate & SRW & Lower & Upper & P-value \\
\hline $\mathrm{X} 11$ & $<-$ & \multirow{6}{*}{ 高 } & 1.000 & .797 & .572 & .913 & .025 \\
\hline $\mathrm{X} 12$ & $<-$ & & 1.128 & .865 & .692 & .958 & .009 \\
\hline $\mathrm{X} 13$ & $<--$ & & .875 & .804 & .636 & .926 & .008 \\
\hline X14 & $<-$ & & .948 & .672 & .429 & .800 & .032 \\
\hline $\mathrm{X} 15$ & $<-$ & & .846 & .627 & .307 & .863 & .011 \\
\hline X16 & $<--$ & & .998 & .713 & .474 & .856 & .014 \\
\hline $\mathrm{X} 21$ & $<-$ & \multirow{6}{*}{ 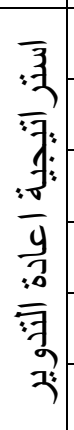 } & 1.000 & .775 & .619 & .884 & .020 \\
\hline $\mathrm{X} 22$ & $<--$ & & .797 & .833 & .634 & .940 & .018 \\
\hline $\mathrm{X} 23$ & $<-$ & & .694 & .790 & .594 & .939 & .004 \\
\hline $\mathrm{X} 24$ & $<-$ & & .768 & .807 & .672 & .878 & .012 \\
\hline $\mathrm{X} 25$ & $<--$ & & 1.014 & .886 & .783 & .960 & .019 \\
\hline $\mathrm{X} 26$ & $<-$ & & .762 & .780 & .552 & .937 & .008 \\
\hline X31 & $<-$ & \multirow{6}{*}{ 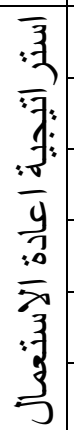 } & 1.000 & .712 & .440 & .874 & .015 \\
\hline X32 & $<-$ & & .828 & .749 & .490 & .903 & .013 \\
\hline X33 & $<-$ & & .875 & .741 & .391 & .955 & .016 \\
\hline X34 & $<-$ & & 1.062 & .824 & .668 & .905 & .030 \\
\hline X35 & $<-$ & & .910 & .744 & .503 & .933 & .006 \\
\hline X36 & $<--$ & & 1.030 & .874 & .709 & .971 & .011 \\
\hline
\end{tabular}

المصدر : بالاعتماد على نتائج مخرجات برنامج (AMOS). 
وكما موضح في الجدول (1) و الذي ييين قيم التشبعات المعيارية ومعنويتها و التي ظهرت غالبيتها اكبر من (0.70) وهي معنوية بدلالة القيم الاحتمالية (P-value) و التي ظهرت

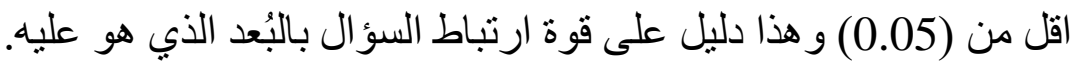

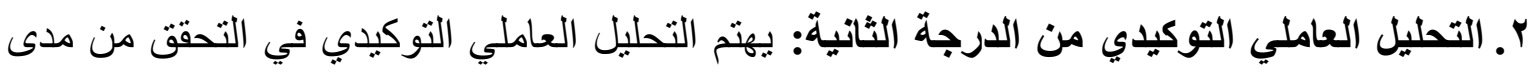

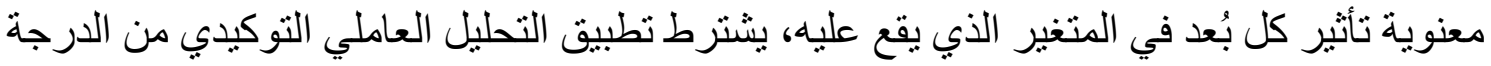

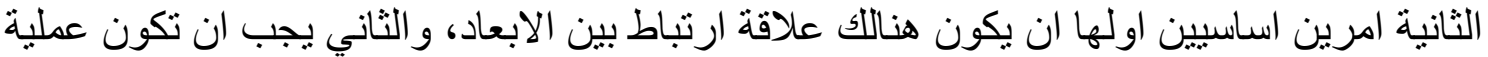

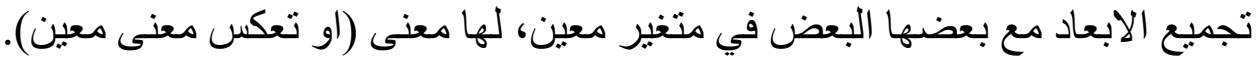

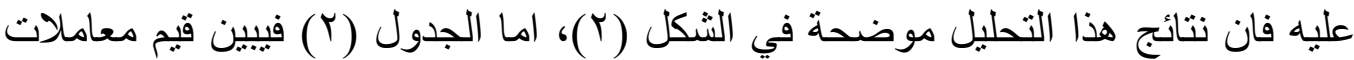

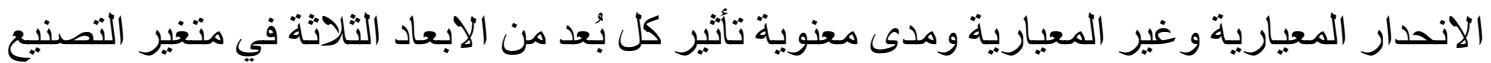

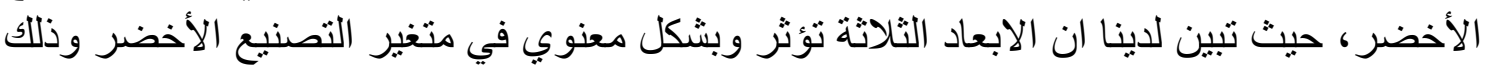

بدلالة القيم الاحتمالية (P-value) و التي ظهرت جميعها اقل من (0.05).

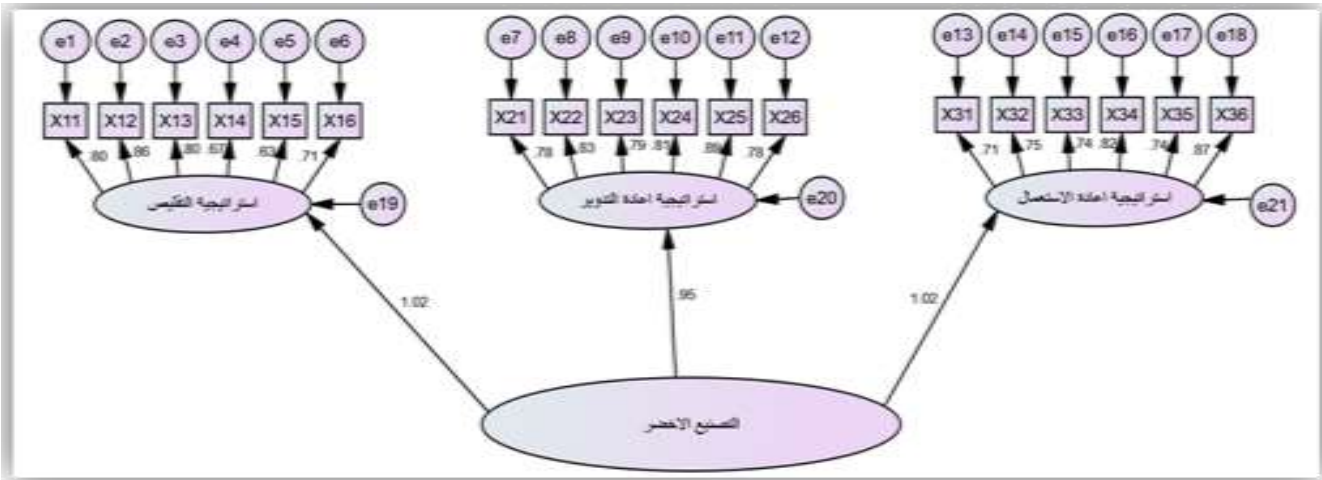

المصدر: بالاعتماد على نتائج مخرجات برنامج (1) (AMOS).

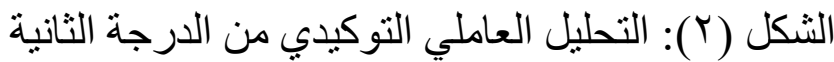

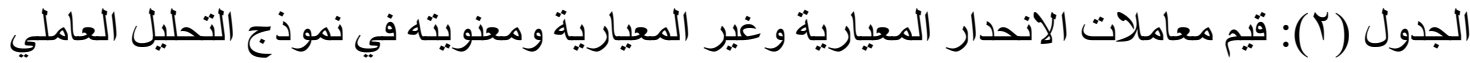
التوكيدي من الدرجة الثانية

\begin{tabular}{|c|c|c|c|c|c|c|c|}
\hline \multicolumn{3}{|c|}{ Parameter } & Estimate & SRW & Lower & Upper & P-value \\
\hline | اعادة الاستعمال & $<-$ & & 1.067 & 1.025 & .983 & 1.102 & .007 \\
\hline اعادة التدويرية & $<-$ & الأخضر & 1.172 & .955 & .824 & 1.011 & .019 \\
\hline التتر اتيجية & $<-$ & & 1.000 & 1.022 & .976 & 1.076 & .005 \\
\hline
\end{tabular}

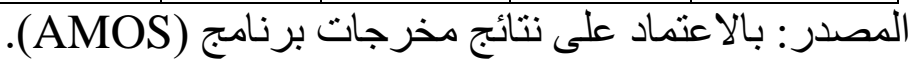

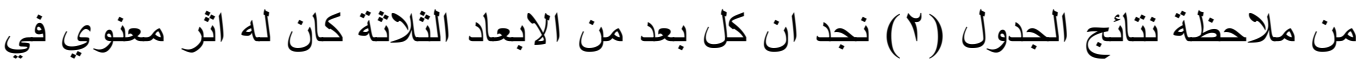

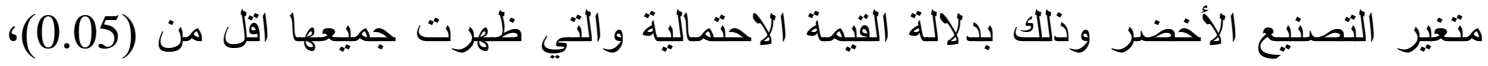

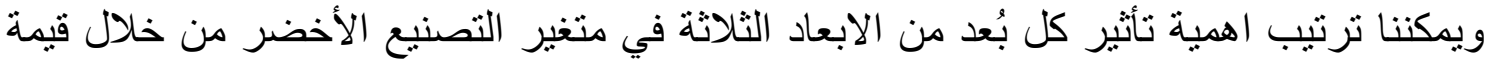

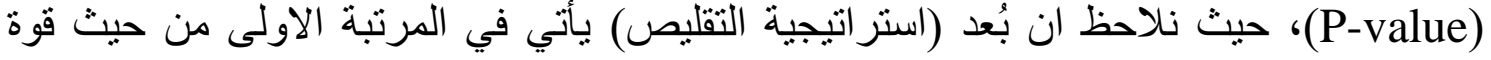

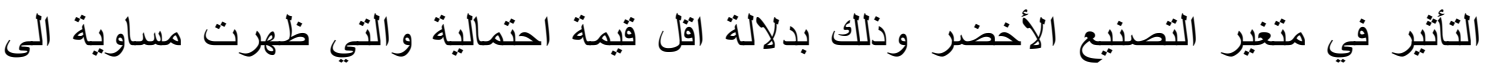


(0.005)، ويأتي في المرتبة الثانية بُعد (استر اتيجية اعادة الاستعمال) وذلك بدلالة القيمة الاحتمالية

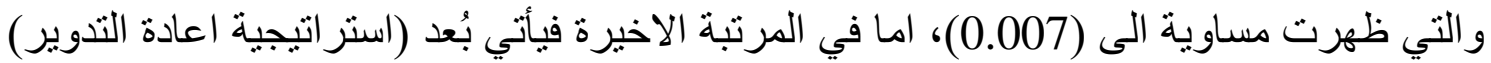

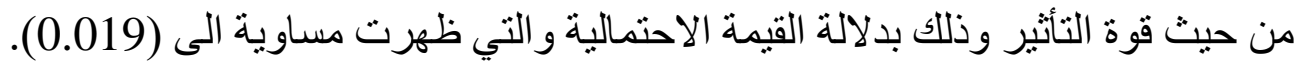
r. الاتساق الداخلي للمتغيرات المدروسة: يعرف الاتساق الداخلي (Internal Consistency) بانه التر ابط بين الاسئلة داخل البعد الواحد، ويجيب الاتساق الداخلي على التساؤل (هل ان الاسئلة تتشبع

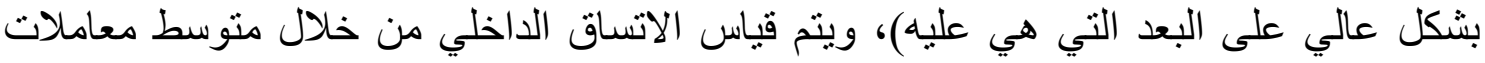

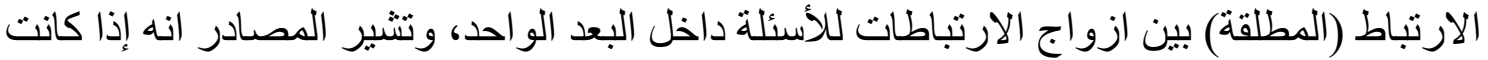

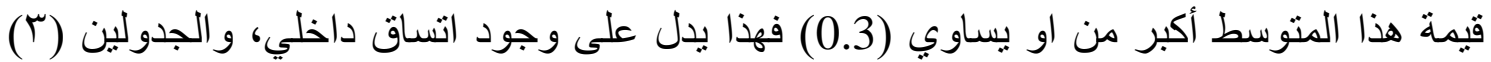

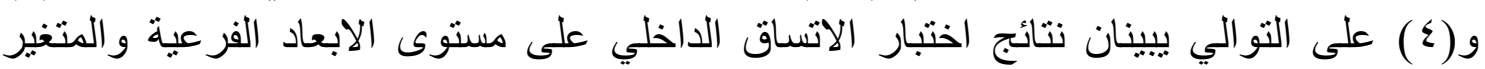
الرئيسي قبد الدر استة: أ. الاتساق الاخلي على مستوى الابعاد الفرعية للمتغير الرئيسي: يظهر الجدول (ب) نتائج وجود

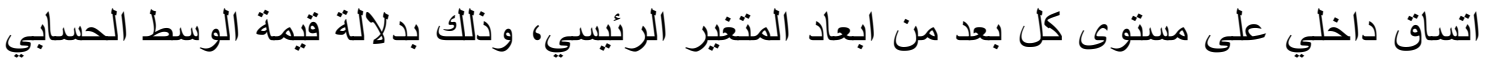

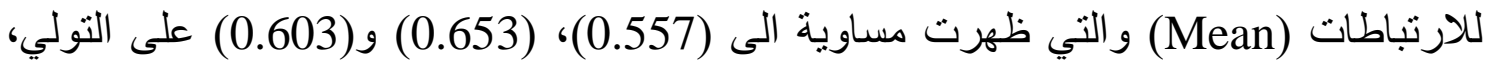
وجميعها أكبر من (0.3). الجدول (ب): قيم الاتساق الداخلي على مستوى الابعاد الفرعية للمتغير الرئيسي

\begin{tabular}{|c|c|c|c|c|c|c|}
\hline \multicolumn{7}{|c|}{ Inter-Item Correlations } \\
\hline الرئيسير & الابعاد الفرعية & Mean & Minimum & Maximum & Variance & $\begin{array}{l}\mathbf{N} \text { of } \\
\text { Items }\end{array}$ \\
\hline \multirow{3}{*}{ الأخضر } & استر اتيجية اعادة الاستعمال & 0.557 & 0.378 & 0.725 & 0.013 & 6 \\
\hline & استر اتيجية اعادة التدوير & 0.653 & 0.501 & 0.762 & 0.006 & 6 \\
\hline & استر اتيجية التقليص & 0.603 & 0.426 & 0.790 & 0.010 & 6 \\
\hline
\end{tabular}

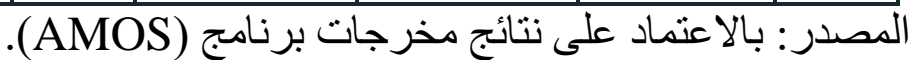
ب. الاتساق الاخلي على مستوى المتغيرات الرئيسية: الجدول (ع): قيم الاتساق الداخلي على مستوى المتغيرنير الرئيسي

\begin{tabular}{|c|c|c|c|c|c|}
\hline \multicolumn{6}{|c|}{ Inter-Item Correlations } \\
\hline المتغير الرئيسي & Mean & Minimum & Maximum & Variance & N of Items \\
\hline التصنيع الأخضر & 0.604 & 0.329 & 0.836 & 0.012 & 18 \\
\hline
\end{tabular}

المصدر : بالاعتماد على نتائج مخرجات برنامج (AMOS). من نتائج الجدول (ع ) اعلاه يتبين لدينا وجود اتساق داخل داخلي على مستوى المتنغير الرئيسي

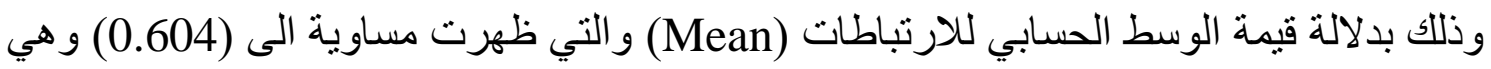
أكبر من (0.3). ثانياً. وصف وتثخيص (استراتيجيات التصنيع الأخضر) في المنظمة المبحوثة: يقدم هذا الجزء

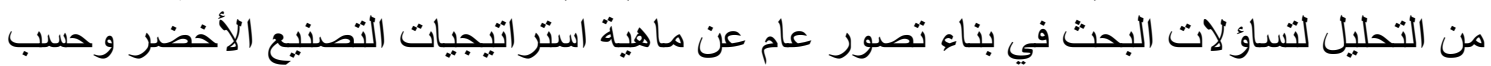

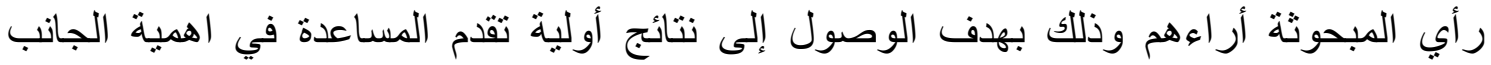
النظري، فمن خلال اختبار تللك الآراء تم الوصول إلى الاستنتاجات، عليه يقدم الجدول ( () نتائج 
(The mean, standard deviation, coefficient of variation, and T.test) مستوى الدلالة حول لاستراتيجيات التصنيع الأخضر بصفتها متغير للبحث بفقراته الفرعيـة (استر اتيجية التقليص، استر اتيجية التدوير ، استر اتيجية اعادة الاستعمال).

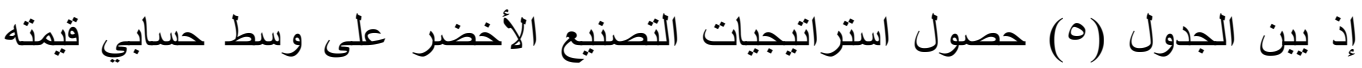

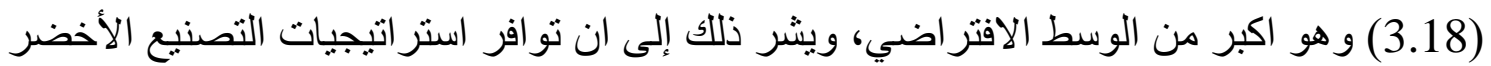

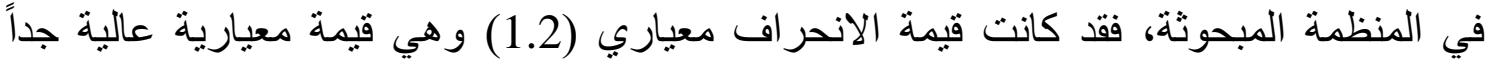

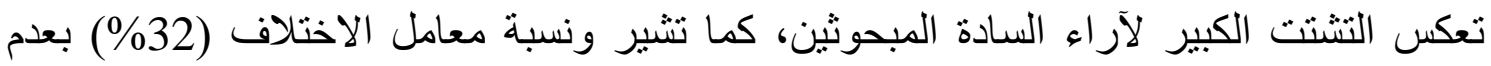
مصداقية في ار اء المبحوثين، وتثير قيمة اختبار T. test البالغة (14.49) إلى تعزيز ذللك عند فئد

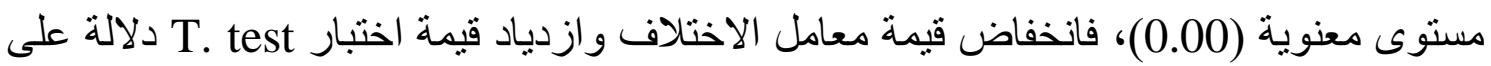
التزام الو اضح للمنظمة باعتماد استراتيجيات التصنيع الأخضر عند عند المستوى المعنوي (0.00) و هي اقل من مستوى المعنوي (0.05) و الذي يدل على وجود تللك الفقرة او ذلك المتغير.

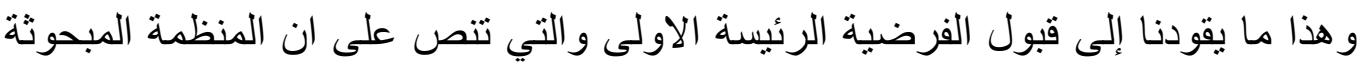

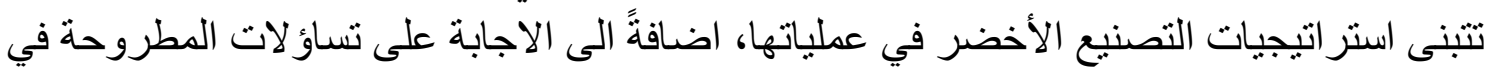

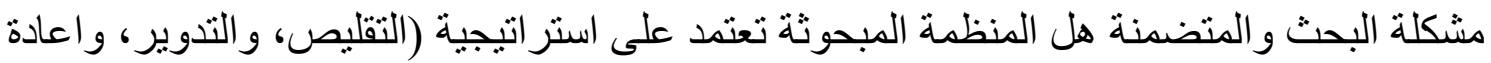
الاستعمال)، وعن طريق المتغيرات الفرعية المشار اليها سيتم قياس استراتيجيات التصنيع

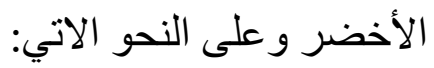

1. وصف وتثخيص استراتيجية التقليص في المنظمة المبحوثة: تشير فقرات المقياس (1 ـالآ) الواردة في الجدول (0) اداة لقياس استراتيجية التقليص و التي تنثير إلى تحقيقها وسطاً حسابياً لجميع فقراته قيمته (3.28) وهو أكبر من الوسط الافتراضي، وكانت قيمة الانحراف المعياري (1.22) وذلك دلالة على موجود نتنت في إجابات المبحوثة أراءهم، وبمعامل اختلاف نسبته

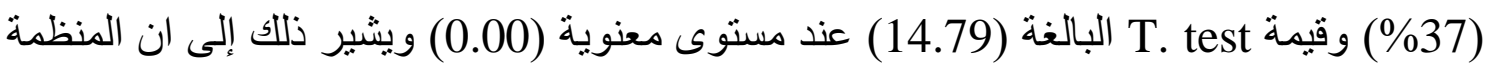
المبحوثة تعتمد على استر اتيجية التقليص.

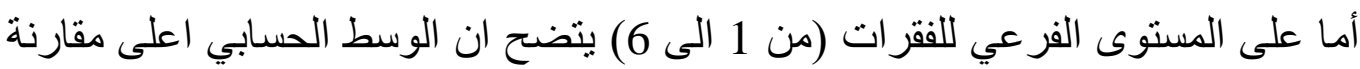
بالوسط الفرضي وجاءت القيم ما بين (3.1-3.57) ويوضح ذللك بزيادة مستوى اهتمام المسؤولين

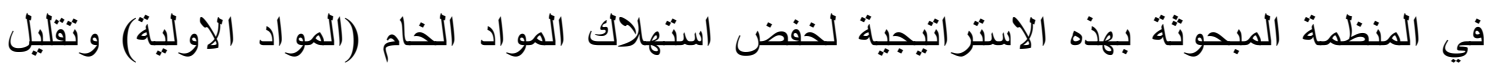

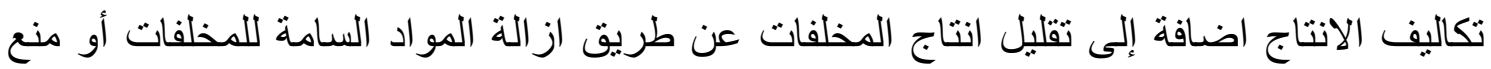

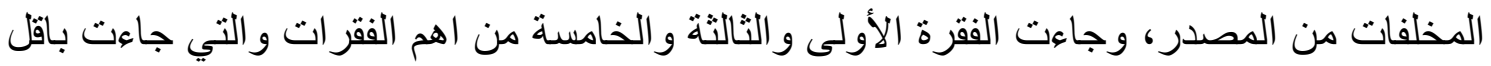

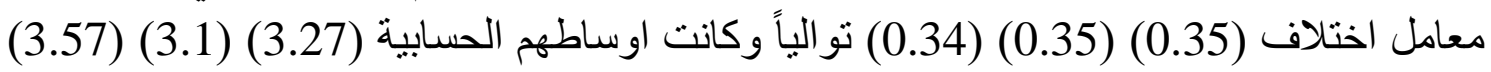

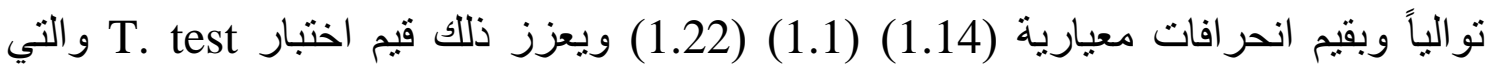

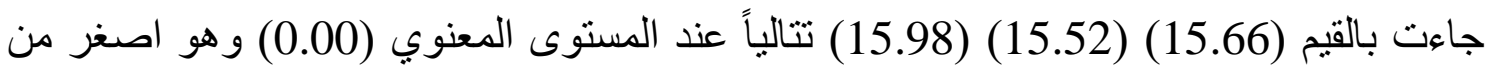
المستوى المعنوي (0.05).

ץ. وصف وتثخيص استراتيجية اعادة التدوير في المنظمة المبحوثةة: تشير فقرات المقياس (من 7

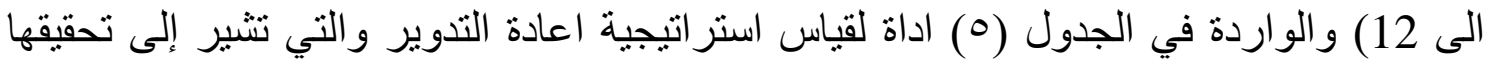

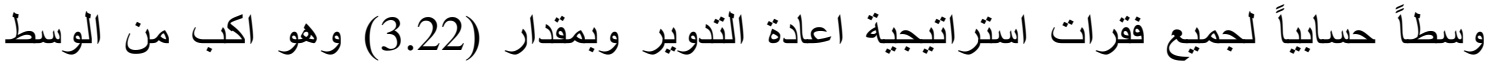

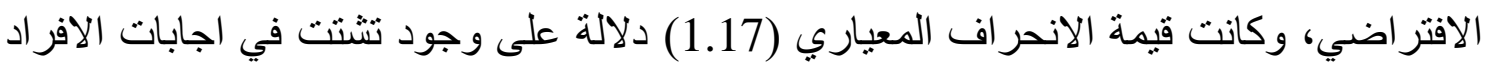

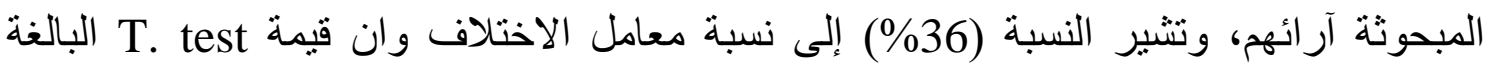


(14.9) عند مستوى معنوية (0.00) وهذه نتيجة جيدة تعني ان المنظمة المبحوثة تعتمد على أنى استر اتيجية التدوير كاستر اتيجية مهمة في اندئ اعمالها.

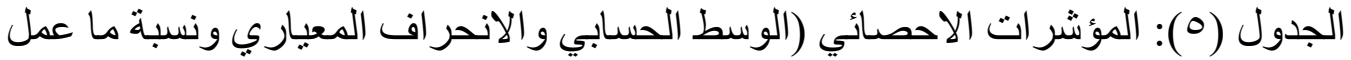

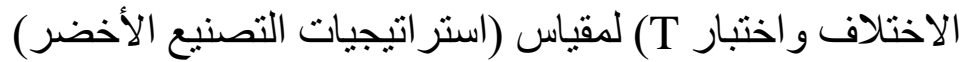

\begin{tabular}{|c|c|c|c|c|c|}
\hline T.test & | الاختلأ & العبلزي & الصنبل الوبط & الثقزن & $\Delta$ \\
\hline 15.6 & 35 & 1.14 & 3.27 & 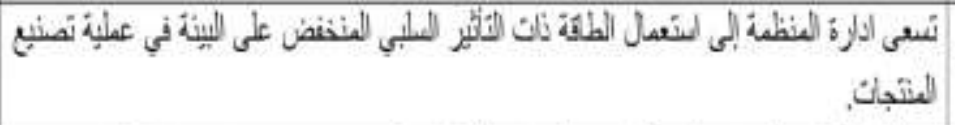 & 1 \\
\hline 14.02 & 40 & 1.22 & 3.13 & 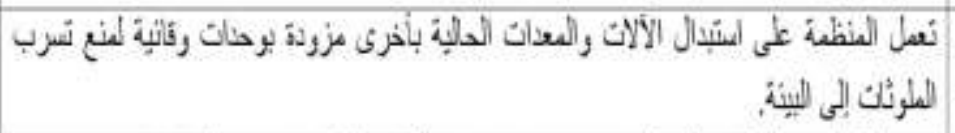 & 2 \\
\hline 15.52 & 35 & 1.1 & 3.1 & 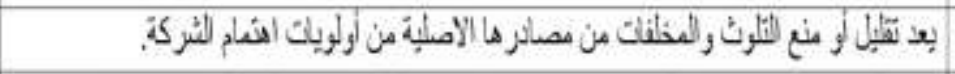 & 3 \\
\hline 12.56 & 43 & 1.34 & 3.1 & 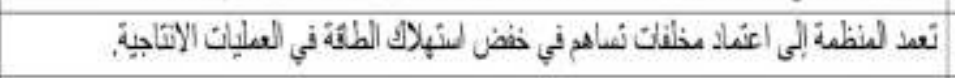 & 4 \\
\hline 15.98 & 34 & 1.22 & 3.57 & 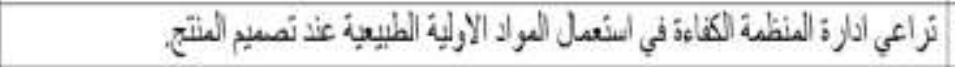 & 5 \\
\hline 14.98 & 37 & 1.28 & 3.5 & 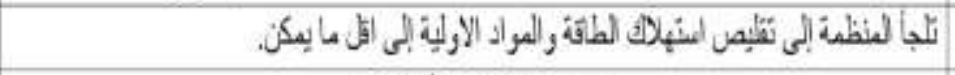 & 6 \\
\hline 14.79 & 37 & 1.22 & 3.28 & 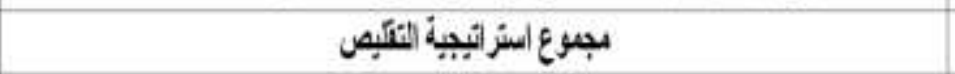 & \\
\hline 13.93 & 39 & 1.29 & 3.27 & 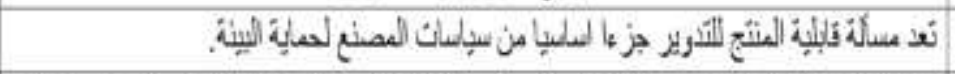 & 7 \\
\hline 15.51 & 35 & 1.22 & 3.47 & كلف الآنتاج & 8 \\
\hline 17.3 & 33 & 1.1 & 3.37 & 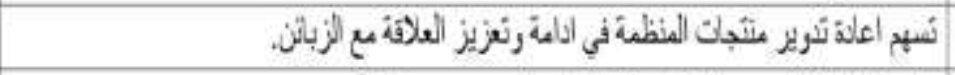 & 9 \\
\hline 15.1 & 37 & 1.14 & 3.1 & 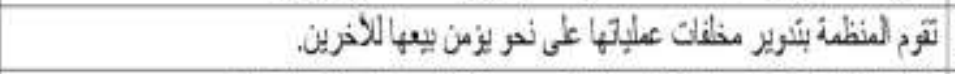 & 10 \\
\hline 12.56 & 37 & 1.14 & 3.1 & 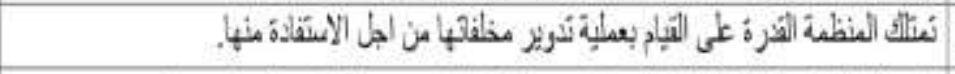 & 12 \\
\hline 15.13 & 37 & 1.1 & 3.0 & 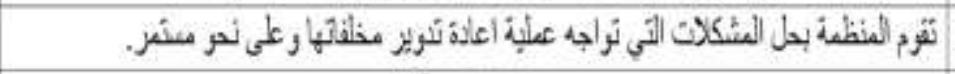 & 13 \\
\hline 14.9 & 36 & 1.17 & 3.22 & مجروع استراتيبهة التكوير & \\
\hline 10.45 & 52 & 1.4 & 2.67 & 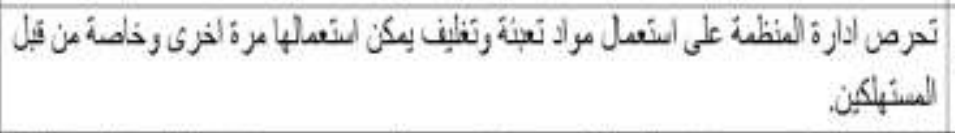 & 14 \\
\hline 16.16 & 40 & 1.12 & 3.3 & 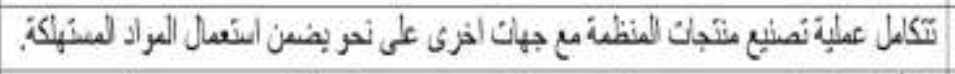 & 15 \\
\hline 14.02 & 39 & 1.16 & 2.97 & 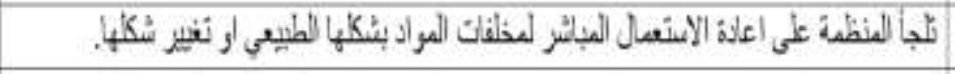 & \\
\hline 13.68 & 40 & 1.24 & 3.1 & 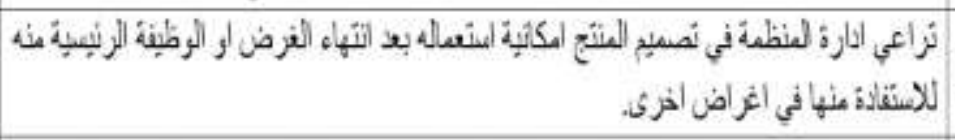 & 16 \\
\hline 13.98 & 40 & 1.19 & 3.0 & 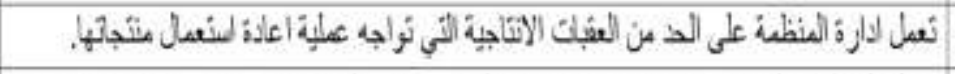 & 17 \\
\hline 14.37 & 38 & 1.22 & 3.24 & 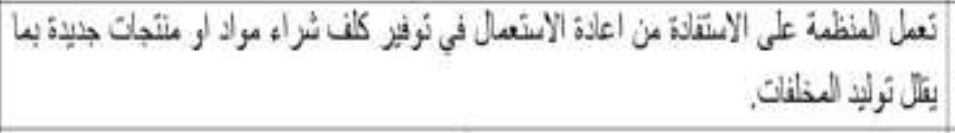 & 18 \\
\hline 13.78 & 42 & 1.22 & 3.05 & مجمرع استرائيبية اعلاة الاستعل & \\
\hline
\end{tabular}

المصدر : من اعداد الباحث اعتماداً على نتائج برنامج SPSS V.22. أما على مستوى الفرعي للفقرات (من 7 إلى 12) يتضح اعد ان الوسط الحسابي جاء مرتفعا بالمقارنة بالوسط الافتر اضي اذ جاءت القيم ما بين (3.30 إلى 3.47) و هذا بدل إلى زيادة مستوى ليطى 


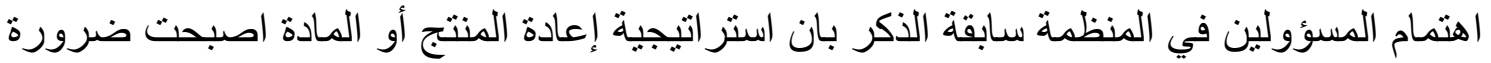
لتدوير المخلفات إلى مو اد مفيدة عن طريق مجموعة معالجات (فيزيائية، أو كيميائية، أو حياتية)

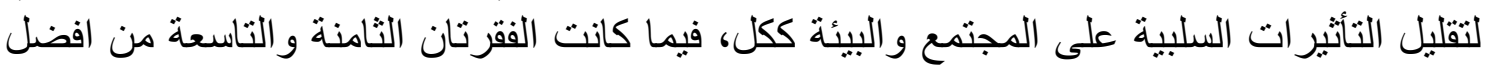

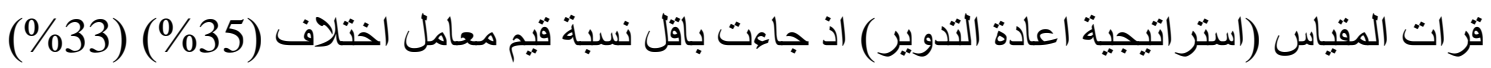

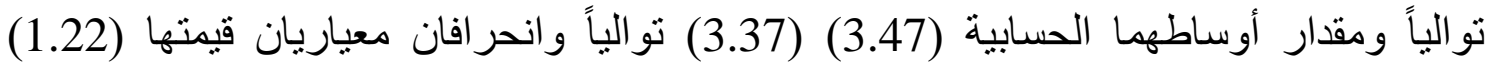

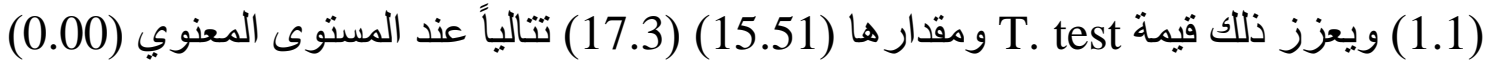
و وهو اقل من المستوى المعنوي (10.05).

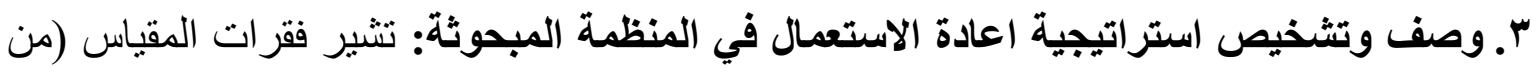

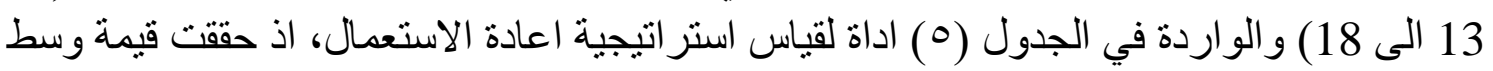

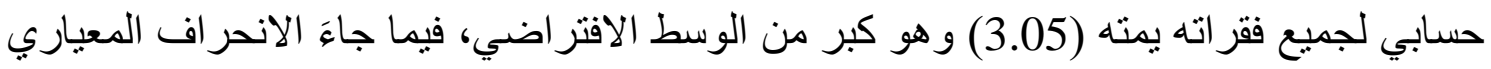

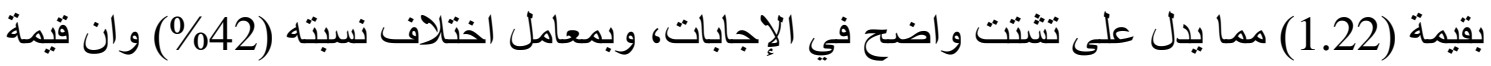

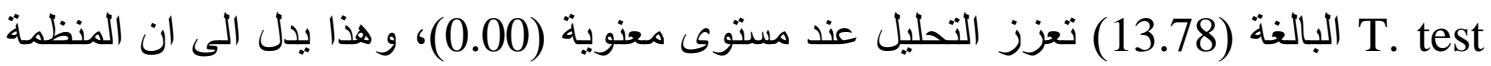

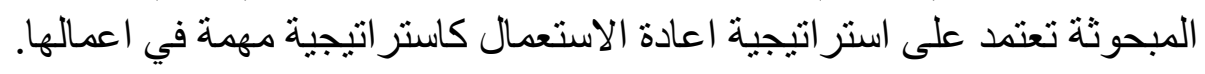

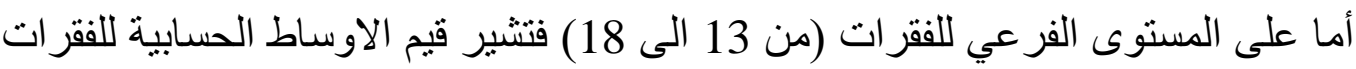

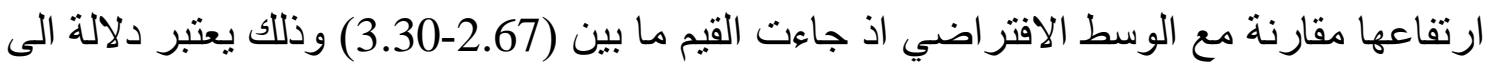

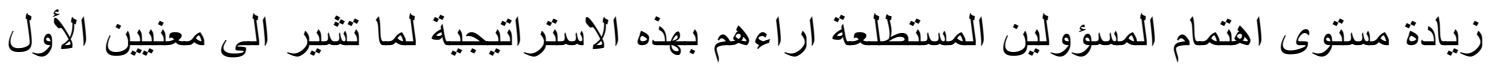

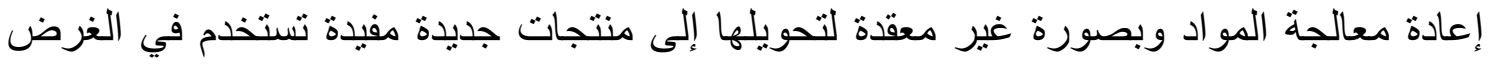

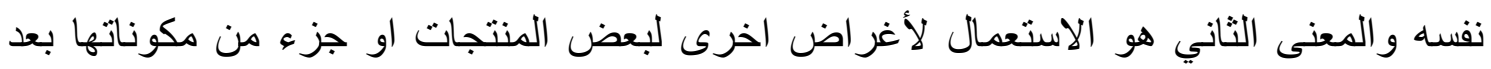

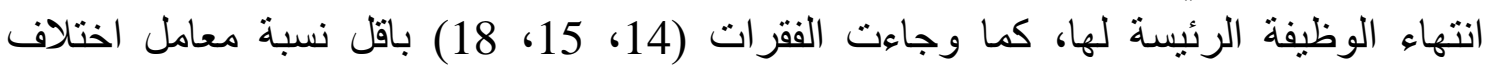

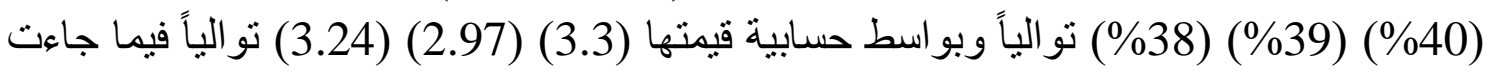

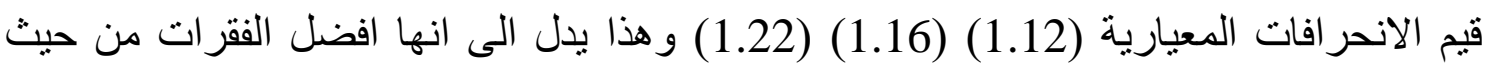

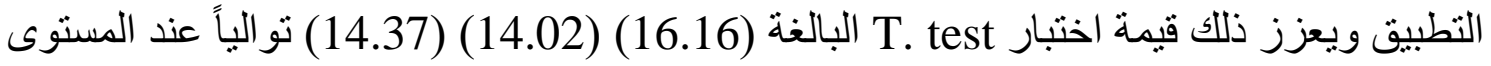
المعنوي (0.00) و هو اقل من المستوى المعنوي (0.05).

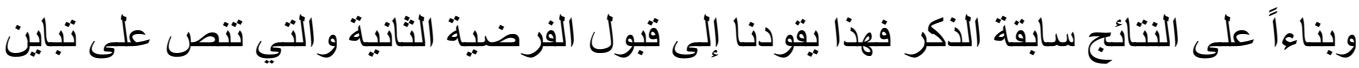

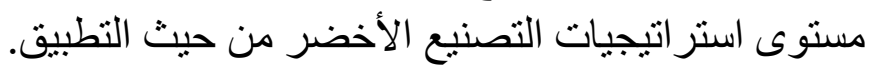

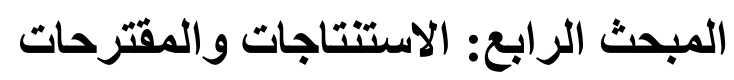

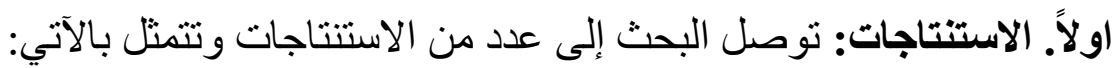

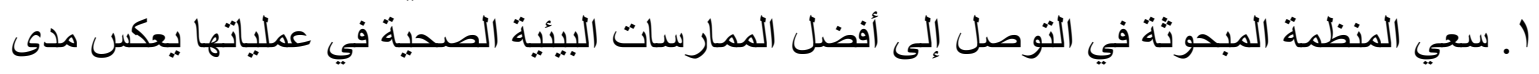

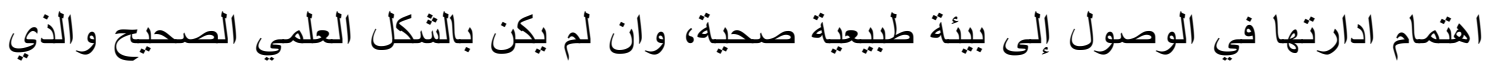

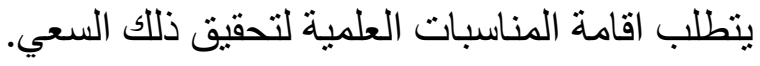

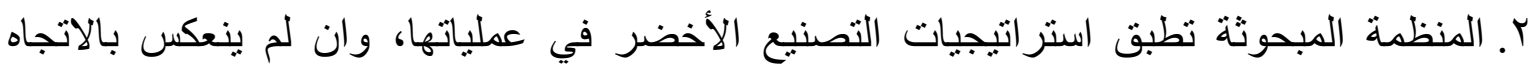

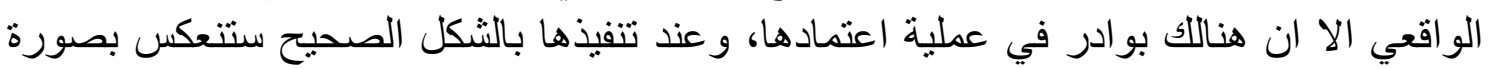

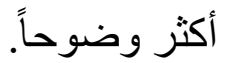

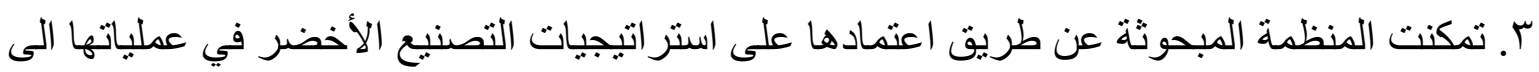

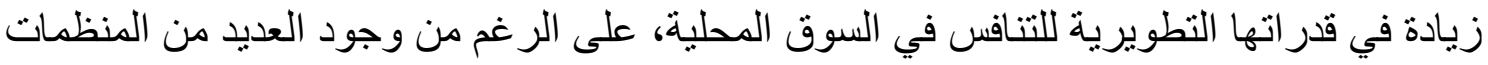

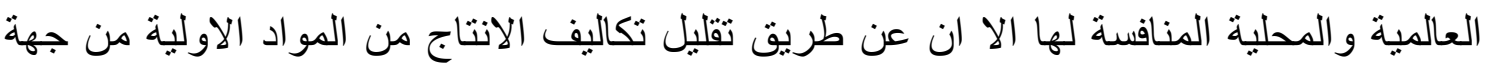


ومحاولة تحقيق هدفها الاجتماعي والبيئي من جهة اخرى وهذا ما تنادي به منظمات الصحة العالمية، جعلها قادرة على النمو و التنافس.

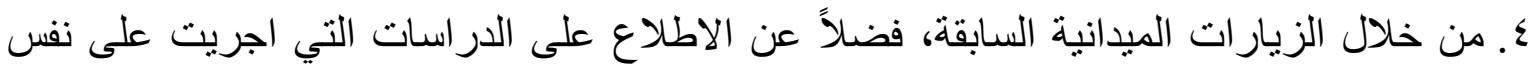

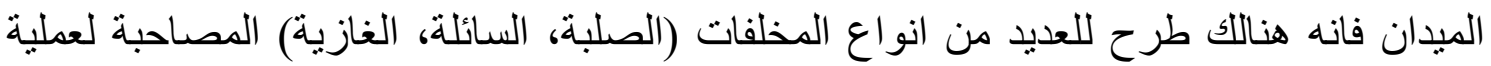

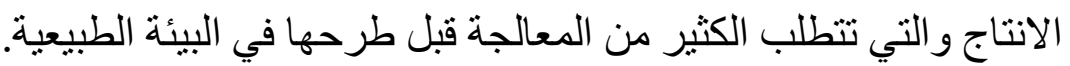
ثانياً. المقترحات: بناءً على النتائج سابقة الذكر والتي انعكست على الاستنتاجات العاتهات اعلاه يقدم البحث

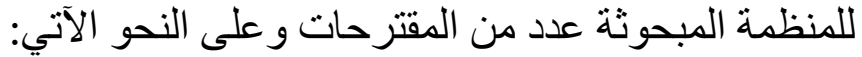

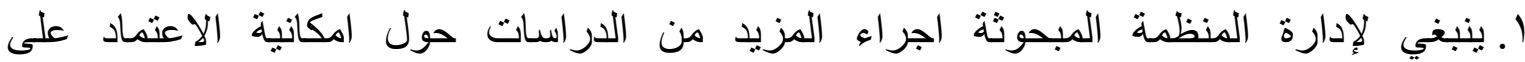

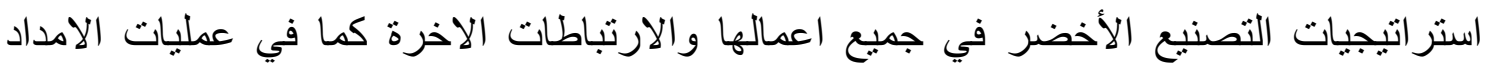

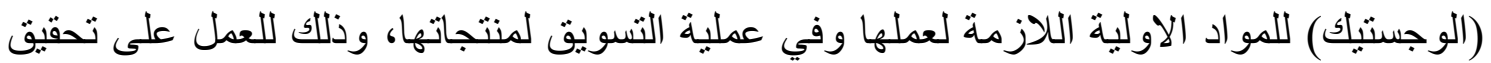
جميع ابعاد التنمية المستدامة عن طريق تخفيض التكاليف (البعد الاقتصادي) ومحافظة على البيئة الطبيعية (البعد البيئي)، و الذي ينعكس على صحة المجتمع ككل (البعد الاجتماعي). Y. على ادارة المنظمة المبحوثة اظهار المزيد من الاهتمام في تطوير عملياتها لتحقيق استر اتيجيات

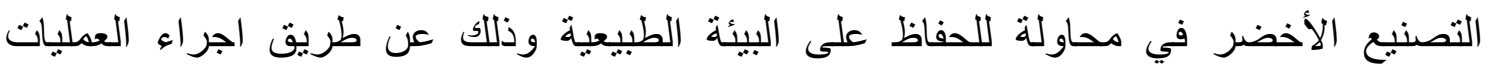

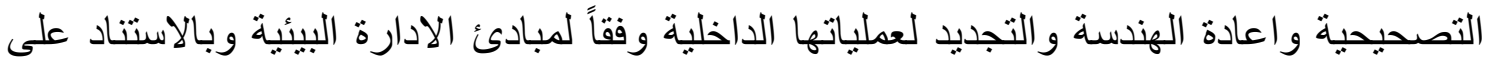
استر اتيجيات التصنيع الأخضر، و العمل على نشر الثقافة البيئية في المنظمات العر اقية.

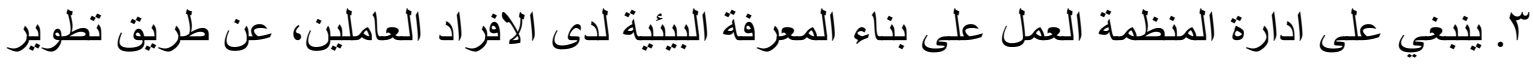
مهار اتهم ومعارفهم وقدر اتهم وتنمية خبر اتهم، وذلك بزجهم في دور ات تدة تدريبية في مجالات كما في

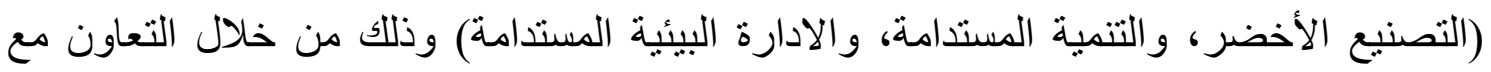
جامعة الموصل لإتمام ذلك. ع. اقامة الندوات وورش العمل المتعلقة بالوصول إلى تحقيق بيئة صحية منميزة، كون عمليات الانتاج

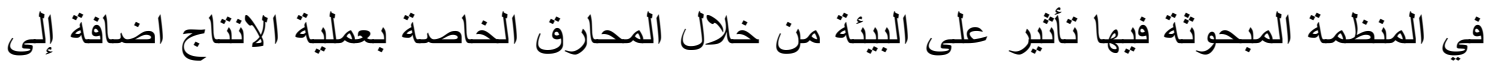
المخلفات الصلبة الملازمة لعملية الانتاج. قائمة المصادر

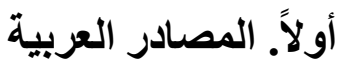

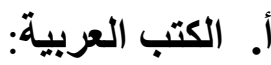

ا. فلاق، محمد، (T ( • ( )، المسؤولية الاجتماعية لمنظمات الاعمال، دار اليازوري العلمية للطباعة

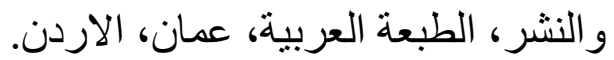
ب. الدوريات:

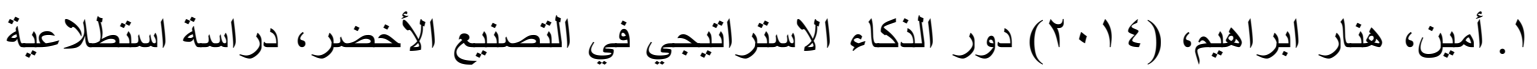
لآراء عينة من المديرين في عينة من مصانع المياه المعدنية في محافظة دهوك، الئ مجلة العلوم

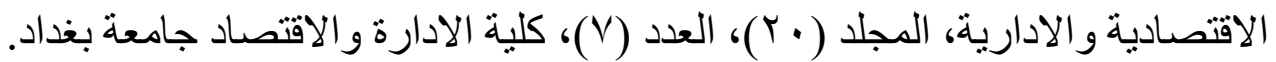

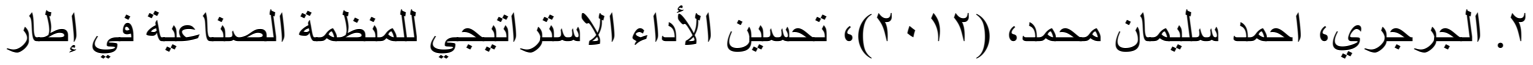
تطبيق استراتيجيات التصنيع البيئي (استراتيجيات التصنيع الأخضر أنموذجا)، دراسة تحليلية

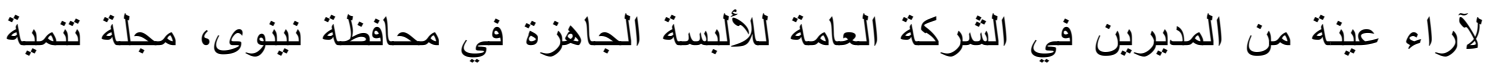
الر افدين، المجلد (0)، العدد (9)، كلية الادارة والاقتصاد، جاءنة جامعة الموصل. 


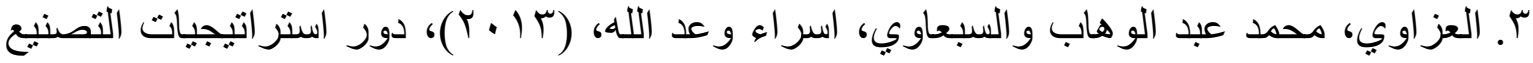

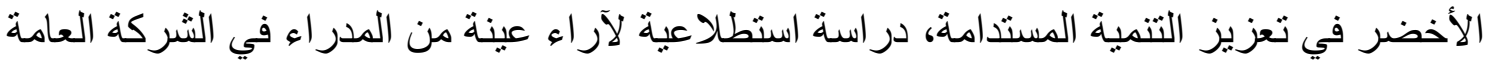

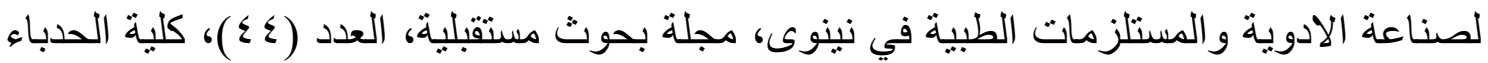

الجامعة، مرك الدر اسات المستقبلية.

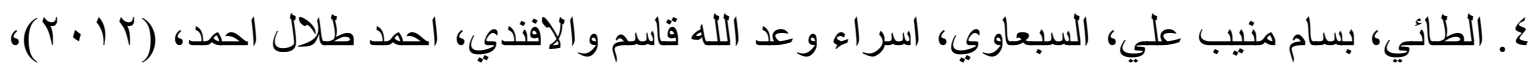
اسهامات بعض انشطة سلسلة التجهيز الخضراء في تعزيز اقامة متطلبات نظام الادارة البيئية

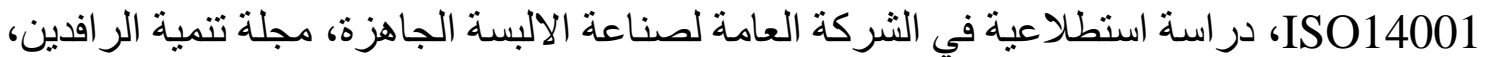

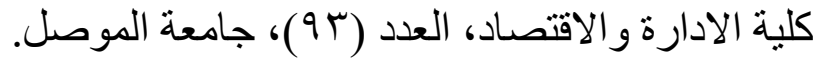

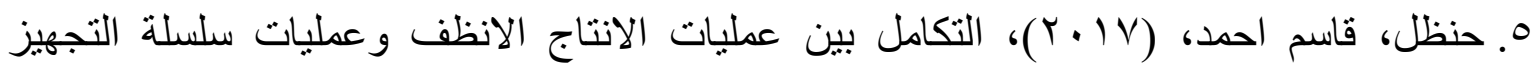
العكسي في الثركات الصناعية: رؤية تطبيقية في شركة الهلال الصناعية في محافظة بغداد، مجلة

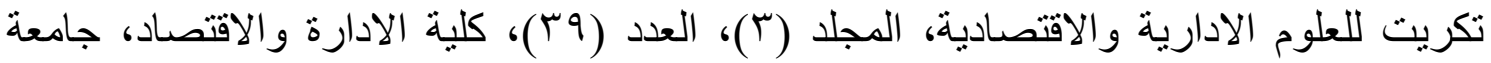
تكريت.

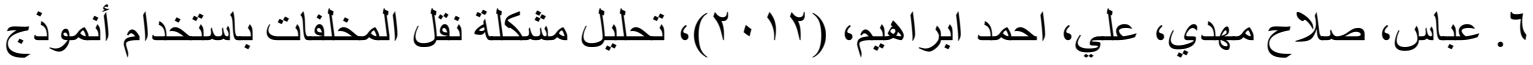

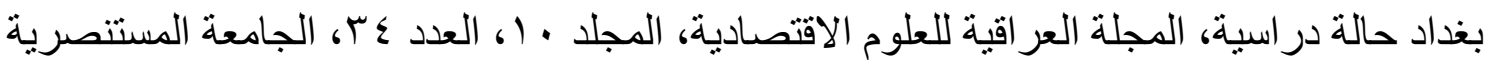
كلية الإدارة و الاقتصاد.

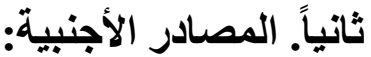

\section{A. Researches}

1. Anindita Bhattacharjee \& Sheetal Kamble \& Akshey Bhargava, (2021), Environmentally Sustainable Municipal Waste Management Strategy- A Case of Jamshedpur, India, Open Access Journal Of Environmental \& Soil Science, Lupine Publishers, LLC, vol. 6 (1), P. 750-757.

2. Arisi, Barbara Maisonnave, (2020), Circular Economy - from waste to resource: 7Rs innovative practices in Amsterdam. Technologie, die nog in de kinderschoenen staan, Rev. Iluminuras, Vol.21, NO 55.

3. Barno, Leah Jemutai, (2014), Green Strategic and Sustainable Development: An Empirical Study, Stratford Peer Reviewed Journals and Book Publishing Journal of Strategic Management, Vol. 5, Issue 1, P 12-19, TF, Bomet University College, Bomet County, Kenya.

4. Bhattacharya, Arindam, Jain, Rahul \& Choudhary, Amar, (2011), Green Manufacturing Energy, Products and Processes, conference of Confederation of Indian Industry Since 1895, The Boston Consulting Group (BCG).

5. Levänen, Jarkko \& Uusitalo, Ville \& Härri, Anna \& Kareinen, Elisa \& Linnanen, Lassi, (2021), Innovative recycling or extended use? Comparing the global warming potential of different ownership and end-of-life scenarios for textiles, journal of Environmental Research Letters, Vol. 16, No. 5.

6. Srinivasan, Venu, (2011), Green Manufacturing: Opening new avenue for growth of Manufacturing Matters-Going Green, Journal of Manufacturing Excellence, confederation of Indian industry. 
7. Yu, A. T. W.; Wong, I.; Wu, Z.; Poon, C.-S., (2021), Strategies for Effective Waste Reduction and Management of Building Construction Projects in Highly Urbanized Cities-A Case Study of Hong Kong, journal of Buildings, V. 11, No. 214.

\section{B. Conferences}

1. Balan, Kumar, (2008), Introduction to Green Manufacturing, the Green Issue Insights from a Machine Manufacturer, Weelabrator Group. The 10th International Conference on Shot Peening September 15-18, 2008 Tokyo, Japan Meiji University.

2. Faridy, Faizatul and Rohendi, Aulia, (2021), The Role of Parents in Engaging Early Childhood to Implement 3R (Reduce, Reuse, Recycle), Advances in Social Science, Education and Humanities Research, Vol. 529, Proceedings of the International Conference on Engineering, Technology and Social Scienc.

\section{Books}

1. Dalhammar, Carl \& Wihlborg, Emelie \& Milios, Leonidas \& Richter, Jessika Luth \& Hoglund, Sahra Svensson \& Russell, Jennifer \& Thidell, Aake, (2021), Enabling Reuse in Extended Producer Responsibility Schemes for White Goods: Legal and Organisational Conditions for Connecting Resource Flows and Actors, Circular Economy and Sustainability, Springer.

2. GBC, (2016), Your Guide to Waste Management in Jordan Waste Sorting Informative booklet, Jordan Green Building Council, ISBN: 978-9957-8751-0-7, Jordan.

3. Hernández, Ana E. \& Bonilla, Lu, \& Tao, Beno, Tomas, \& Fredriksson, Claes, \& Jawahir, Ibrahim S., (2019), Process Sustainability Evaluation for Manufacturing of a Component with the 6R Application, Institute for Sustainable Manufacturing Faculty Publications. Elsevier.

4. Ranjan, Sanjeev, Krishnan CSR \& Kumar, Prashant, (2014), Greening for Future, TATA Consulting Service (TCS) Experience Certainty IT Service Business Solutions Outsourcing, approach for Metals and Mining Industry.

5. Stough, Bill, (2010), Green Manufacturing Using Sustainable Development Principles to Achieve Greener Manufacturing on the Shop Floor, Sustainable Research Group (SRG) Western Michigan University, USA.

\section{Internet}

1. Atlas, Mark \& Florida, Richard, (1998) Green Manufacturing, Carnegie Mellon University-USA. www.creativeclass.comlrfcgdb

2. Lynch, John, H, Readon, Tara. G \& Demay, Bruce. R, (2012), Green Manufacturing in New Hampshire-USA.

https://www.nhes.nh.gov/elmi/products/documents/green-construction.pdf

3. Rastogi, Swati, (2001), Green Manufacturing OISM470W. https://www.jxdoc.com/b-5c47274769eae009581bec49.html

4. United Nations Environment Programme, 2011.

5. Wycoff, Andrew, (2011), OECD Sustainable Manufacturing Toolkit Seven Steps To Environment Excellence. https://www.oecd.org/innovation/green/toolkit/48704993.pdf 


\section{الملحق (1): اداة جمع البيانات \\ بسم اللاه الرحمن الرحيم}

$$
\text { وزامعة الموصلية التعليم العالي والبحث العلمي }
$$

\section{م / م استمارة الاستبانة}

السادة المحتر مين.

تحية طيية وبعد:

تمثل استمارة الاستبانة هذه جزءاً من متطلبات إعداد بحث ميداني في إدارة الأعمال

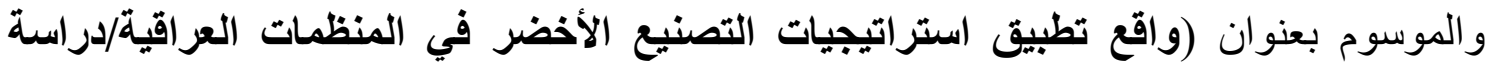
استطلاعية في معمل اسمنت بادوش في محافظة نينوى).

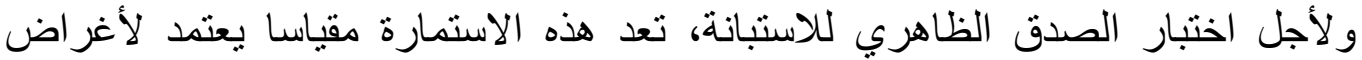
البحث العلمي، وان تفضلكم بالإجابة المناسبة يسهم في الحصول على نتائج دقيقة بما يعزز تحقيق أهداف البحث، علماً إن الإجابات تستخدم لأغر اض البحث العلمي دون الحاجة لذكر الاستة مع فائق الثكر و التقدير ملاحظة: مع فالقال

' يأمل الباحث من شخصكم الكريم قر اءة جميع العبار ات أولًا ثم البدء بتأثنير كل منها ضمن سلم الإجابة وبما يعبر عن موققكم الدقيق. ץ. يرجى الإجابة عن جميع الأسئلة لأن ترك أي سؤال دون إجابة يعني عدم صلاحية الاستمارة للتحليل.

ז. ليس هنالك إجابة صحيحة أو خاطئة، فنحن نطلب ر أيكم الصريح و الدقيق في السؤال المطروح.

\begin{tabular}{|c|c|c|c|c|c|c|}
\hline لا لاوافق & اوافق & 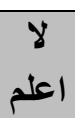 & اوفق & 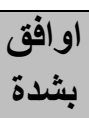 & الفقرة & ت \\
\hline & & & & & 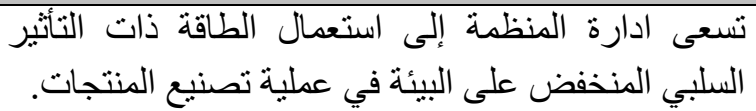 & .1 \\
\hline & & & & & تبأخرى مزودة المنظمة على استبدال الآلات و المعدات الحالية & r \\
\hline & & & & & يعد تقليل أو منع التلوث و المخلفات من مصادر ها الاصلية & r. \\
\hline & & & & & تعمد المنظمة إلى اعتماد العماد مخلفات تساهم في خفض الانتاجية. &.$\varepsilon$ \\
\hline & & & & & تراعي ادارة المنظمة الكفاءة في استعمال المواد الاولية & 0 \\
\hline & & & & & تلجأ المنظمة إلى تقليص استهلاك الطاقة و المو اد الاولية & 7.7 \\
\hline
\end{tabular}

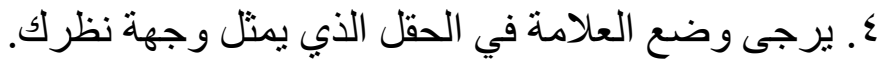
๑. رابط الاستمارة الالكترونية للحصول على البيانات (https:/forms.gle/22T3P5857PC8Tys6A). 


\begin{tabular}{|c|c|c|c|c|c|c|}
\hline لا لاوافق & 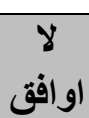 & 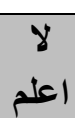 & اوفق & 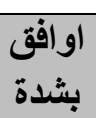 & الفقرة & ت \\
\hline & & & & & تعد مسألة قابلية المنتج للتدوير جزء ال اساسيا من سياسات &.$v$ \\
\hline & & & & & الكفاءة المنظمة إلى العمال المخلفاد تدوير منتجاتها بهدف نحو يخف كلف &.$\wedge$ \\
\hline & & & & & تسهم اعادة تدوير منتجات المنظمة في ادامة وتعزيز & .9 \\
\hline & & & & & تيعها للآخرين. & 1. \\
\hline & & & & & تمتلك المنظمة القدرة على القيام بعملية تدوير مخلفاتها من & 11 \\
\hline & & & & & تدوير مخلفاتها وعلى نحل المشو مستمرت التي تواجه عملية اعادة & ir \\
\hline & & & & & تمكن استعمالها مرة ادرى المنظمة على استعمال موادة من قبل المستئة وتغليف. & r \\
\hline & & & & & 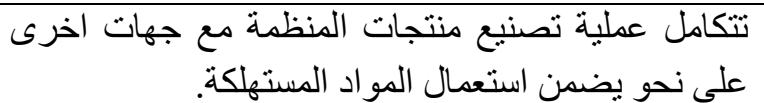 & $1 \leq$ \\
\hline & & & & & المواد المنظمة على اعلى الطبيعي او تغيير شكلها. الاستعال المباشر لمخلفات & 10 \\
\hline & & & & & 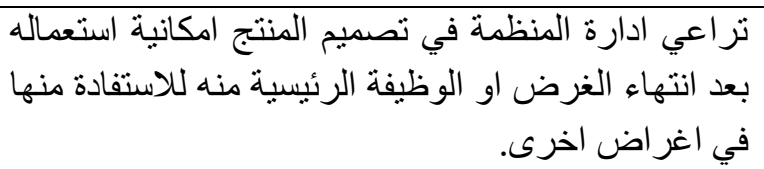 & 17 \\
\hline & & & & & تعمل ادارة المنظمة علية اعلى الحدة من العتعمال منتجاتها. & iv \\
\hline & & & & & توفير كلف شراء المنظة على الاستفادة من او منتجات جديدة بما يقلاد توليد في & 11 \\
\hline
\end{tabular}

